Working Paper 9602

\title{
AGENCY COSTS, NET WORTH, AND BUSINESS FLUCTUATIONS: A COMPUTABLE GENERAL EQUILIBRIUM ANALYSIS
}

by Charles T. Carlstrom and Timothy S. Fuerst

Charles T. Carlstrom is an economist at the Federal Reserve Bank of Cleveland, and Timothy S. Fuerst is an associate professor of economics at Bowling Green State University and a consultant at the Federal Reserve Bank of Cleveland.

Working papers of the Federal Reserve Bank of Cleveland are preliminary materials circulated to stimulate discussion and critical comment. The views stated herein are those of the authors and not necessarily those of the Federal Reserve Bank of Cleveland or of the Board of Governors of the Federal Reserve System.

Working papers are now available electronically through the Cleveland Fed's home page on the World Wide Web:

http://www.clev.frb.org.

May 1996 


\begin{abstract}
This paper develops a computable general equilibrium model in which endogenous agency costs can potentially alter business cycle dynamics. The model resembles the influential theoretical work of Bernanke and Gertler (1989), from whom we borrow our title. The model is calibrated to match key features of U.S. aggregate activity. Two sources of shocks are considered: shocks to the distribution of wealth and shocks to aggregate productivity. We reach two conclusions. First, "debt-deflations" can have a significant and persistent effect on real activity. In the case of large monitoring costs, a relatively small wealth redistribution (corresponding to a one-time annual surprise inflation of 1.0 percent) leads to a 0.5 percent increase in investment spending. Second, the agency-cost model naturally delivers a hump-shaped investment response to a productivity shock. This is because households delay their investment decisions until agency costs are at their lowest, a point in time several periods after the initial shock.
\end{abstract}




\section{Introduction}

At least since Irving Fisher's (1933) "debt-deflation" explanation of the Great Depression, many economists have viewed financial factors, such as borrower net worth, as important elements of business cycle fluctuations. The familiar story goes something like this. To engage in investment opportunities, entrepreneurs must partially rely on external finance. This borrowing is typically limited because of the agency costs involved. An aggregate shock that transfers wealth from entrepreneurs to lenders will lower aggregate investment because this wealth redistribution will increase the need for external finance and thus lead to greater agency costs. These shocks can then be propagated forward because the lower level of investment today tends to lead to lower levels of capital, output, and net worth tomorrow.

A seminal contribution to this line of research was made by Bernanke and Gertler (1989) (hereafter denoted as BG). BG developed a general equilibrium model in which agency costs arise endogenously. This is a nontrivial exercise because these agency problems arise only in a setting in which the Modigliani-Miller theorem does not hold. We borrow our title from BG because, in this paper, we build on their work by constructing a calibrated, computable general equilibrium model that can capture quantitatively the effects that BG analyze qualitatively. Our study thus also builds on Fuerst (1995), which provided a first attempt at quantitatively modeling the BG environment. We view this paper as a preliminary step in a larger research program that will quantitatively investigate the role of agency costs in general equilibrium business cycle models. The BG model is a natural place to begin this line of research because it is both well known and quite influential within the profession.

An important innovation in the current paper is to model the entrepreneurs as long 
lived. ${ }^{1}$ BG ignore this issue by analyzing a Diamond-type (1965) overlapping generations model in which entrepreneurs make investment decisions in only one period. Although Fuerst (1995) assumes that households are infinitely lived, he follows BG by assuming that entrepreneurs live for only a single period. Allowing for long-lived entrepreneurs is potentially difficult because the contracting problem between lenders and entrepreneurs then takes on the characteristics of a repeated game with moral hazard. ${ }^{2}$ We ignore much of this difficulty by assuming that there is enough interperiod anonymity so that financial contracts can depend only on an entrepreneur's level of net worth, and not on his entire past history of debt repayment (although history of course plays a role in that it affects the current level of net worth).

Even with this simplification, we still have the problem of heterogeneity. At any point in time, there will be a great deal of net-worth heterogeneity across entrepreneurs, and keeping track of the net-worth distribution and of how it affects the aggregate economy is in general quite difficult. However, by assuming a linear investment and linear monitoring technology, we are able to exploit an aggregation result: Only the first moment of the distribution of entrepreneurial net worth has any effect on the aggregate economy. Keeping track of the mean is quite easy, and amounts to simply adding an additional state variable to the dynamic program.

The paper reaches two main conclusions. First, debt-deflations can have a significant and persistent effect on real activity. In the case of large monitoring costs, a relatively small wealth redistribution (corresponding to a one-time annual 1 percent surprise inflation) leads to a 0.5 percent increase in investment spending.

\footnotetext{
The importance of long-lived entrepreneurs was also suggested by Gertler (1995) in his comments on Fuerst (1995).

${ }^{2}$ See Gertler (1992) for a theoretical analysis of an agency-cost model in which entrepreneurs write two-period contracts.
} 
Second, the agency-cost model naturally delivers a hump-shaped investment response to a productivity shock. This is because households delay their investment decisions until agency costs are at their lowest--a point in time several periods after the initial shock. This second conclusion is related to the first. The hump-shaped investment response occurs because the productivity shock increases the return to internal funds, which in turn redistributes wealth from households to entrepreneurs. The investment response thus mirrors the hump-shaped behavior of entrepreneurial net worth.

A related attempt to model long-lived entrepreneurs is provided by Kiyotaki and Moore (1995). There are two distinct differences between the current paper and theirs. First, the underlying contracting environment in Kiyotaki and Moore is quite different. They build on the work of Hart and Moore (1994), which analyzes the contracting problem in an environment with ex post renegotiation and the inalienability of human capital. One implication of the Kiyotaki-Moore contract is that borrowing is so tightly constrained by the level of net worth that default never occurs in equilibrium. In contrast, we follow BG and adopt the costly state verification model of Townsend (1979). Here, lending exceeds net worth, so that default is an equilibrium phenomenon. A second difference between this paper and Kiyotaki and Moore is that we attempt to quantify the effects of agency costs in an otherwise standard real business cycle (RBC) model.

Section 2 of the paper develops the optimal financial contract in a partial equilibrium setting and demonstrates the aggregation result that is so important in the sequel. Section 3 lays out the complete general equilibrium environment. Section 4 discusses calibration, and sections 5 and 6 present our numerical results. We conclude in section 7. 


\section{The Financial Contract}

In this section, we consider the financial contract in a partial equilibrium setting. This financial contract generates an upwardly sloped supply curve for investment goods. In the next section, we will embed this supply curve into an otherwise standard RBC model. We are able to separate consideration of the contract from the rest of the general equilibrium model because the contract is only one period in length--it is negotiated at the beginning of a period and resolved by the end of that same period. General equilibrium issues affect the contract through the level of entrepreneurial net worth, $\mathrm{n}>0$, and through the aggregate price of capital, $\mathrm{q}>0$. For the purposes of this section, we will take $\mathrm{n}$ and $\mathrm{q}$ parametrically.

The contract consists of two parties: an entrepreneur with net worth $n>0$, and a lender with resources that he may wish to lend to the entrepreneur. Both are assumed to have risk-neutral preferences over end-of-period consumption. ${ }^{3}$

The entrepreneur has access to a stochastic technology that contemporaneously transforms i consumption goods into $\omega$ i units of capital. The random variable $\omega$ is i.i.d. across time and across entrepreneurs, with distribution $\Phi$, density $\phi$, a non-negative support, and a mean of unity. Agency issues are introduced into the environment by assuming that $\omega$ is privately observed by the entrepreneur. Others can privately observe $\omega$ only at a monitoring cost of $\mu$ i capital units, i.e., the attempt to monitor the project results in the destruction of $\mu \mathrm{i}$ units of capital. This informational asymmetry creates a moral hazard problem because, absent monitoring, the entrepreneur may wish to misreport

\footnotetext{
${ }^{3}$ In the next section, risk-averse households will be the source of loanable funds to the entrepreneurs. However, in terms of the financial contract, they will be effectively risk neutral because 1) there will be no aggregate uncertainty over the duration of the contract, and 2) they will carry out their lending through a capital mutual fund (CMF). By funding a large number of entrepreneurs, the CMF will take advantage of the law of large numbers to eliminate idiosyncratic entrepreneurial uncertainty and guarantee a sure return to the households.
} 
the true value of $\omega$. The optimal contract will be structured in such a way that the entrepreneur will always truthfully report the $\omega$ realization. Note that the capital production and monitoring technologies each exhibit constant returns to scale. This assumed linearity is the source of the aggregation result below.

To make the asymmetric information problem relevant, assume that net worth is sufficiently small so that entrepreneurs would like to receive some external financing from firms. Gale and Hellwig (1985) and Williamson (1987a) have demonstrated that in environments of this type, the optimal contract between lenders and entrepreneurs is risky debt. ${ }^{4}$ The contract will be characterized by an interest rate $\mathrm{r}^{\mathrm{k}}$. An entrepreneur who borrows $(i-n)$ consumption goods agrees to repay $\left(1+r^{k}\right)(i-n)$ capital goods to the lender. The entrepreneur will default if the realization of $\omega$ is "low," i.e., if $\omega<$ $\left(1+r^{k}\right)(i-n) / i \equiv \bar{\omega}$. The lender will monitor the project outcome only if the entrepreneur defaults, in which case it will confiscate all the returns from the project. Note that the contract is completely defined by the pair $(i, \bar{\omega})$, and that it is convenient to consider the optimization problem over these two arguments. Once the optimal $(\mathrm{i}, \bar{\omega})$ have been found, one can then back out the implied lending rate of interest, $\left(1+r^{k}\right) \equiv \bar{\omega} i /(i-$ n). Under the contract (with $q$ denoting the end-of-period price of capital), expected entrepreneurial consumption is given by

$$
\mathrm{q}\left[\int_{\bar{\omega}}^{\infty} \omega \mathrm{i} \Phi(\mathrm{d} \omega)-(1-\Phi)\left(1+\mathrm{r}^{\mathrm{k}}\right)(\mathrm{i}-\mathrm{n})\right]
$$

Using the definition of $\bar{\omega}$, this can be simplified to

\footnotetext{
4In addition, we must assume that a commitment device exists, and that stochastic monitoring is impossible. See, for example, Townsend (1979) and Prescott and Townsend (1984). In contrast, BG allow for the possibility of stochastic monitoring so that the optimal contract cannot be interpreted as risky debt. Recent work by Boyd and Smith (1994) suggests that (in a quantitative sense) there is little loss of generality in restricting the contract to pure strategies.
} 


$$
\operatorname{qif}(\bar{\omega}) \equiv \operatorname{qi}\left\{\int^{\infty} \omega(\mathrm{d} \omega)-[1-\Phi(\bar{\omega})] \bar{\omega}\right\}
$$

$\bar{\omega}$

where $f(\bar{\omega})$ is interpreted as the fraction of the expected net capital output received by the entrepreneur. Similarly, the expected consumption of the lender on such a contract is given by

$$
\mathrm{q}\left[\int_{0}^{\bar{\omega}} \omega \mathrm{i} \Phi(\mathrm{d} \omega)-\Phi \mu \mathrm{i}+(1-\Phi)\left(1+\mathrm{r}^{\mathrm{k}}\right)(\mathrm{i}-\mathrm{n})\right]
$$

or

$$
\operatorname{qig}(\bar{\omega}) \equiv \operatorname{qi}\left\{\int_{0}^{\bar{\omega}} \omega \Phi(\mathrm{d} \omega)-\Phi(\bar{\omega}) \mu+[1-\Phi(\bar{\omega})] \bar{\omega}\right\}
$$

where $g(\bar{\omega})$ is interpreted as the fraction of the expected net capital output received by the lender. Note that

$$
\mathbf{f}(\bar{\omega})+\mathbf{g}(\bar{\omega})=1-\Phi(\bar{\omega}) \mu,
$$

so that on average, $\Phi(\bar{\omega}) \mu$ of the produced capital is destroyed by monitoring, and the remainder is split between the entrepreneur $[f(\bar{\omega})]$ and lender $[g(\bar{\omega})]$.

The optimal contract is given by the $(i, \bar{\omega})$ pair that maximizes the entrepreneur's expected return subject to the lender being indifferent between loaning the funds and retaining them. ${ }^{5}$ More precisely, the optimal contract is given by the solution to

$$
\max \text { qif }(\bar{\omega}), \text { subject to } \operatorname{qig}(\bar{\omega}) \geq(\mathrm{i}-\mathrm{n}) \text {. }
$$

An additional constraint guarantees the participation of the entrepreneurs, namely,

${ }^{5}$ We are assuming that the economic rents generated by the contract flow to the entrepreneur--an assumption that is quite plausible given that entry into lending is more likely than entry into entrepreneurial activity. Also, since these loans are intraperiod, the opportunity cost of the funds is simply (i-n). 
qif $(\bar{\omega}) \geq \mathrm{n}$, which will always be satisfied below. It is also straightforward to show that the entrepreneur will always want to invest all of his net worth in his own project. The first-order conditions to the problem include

$$
\begin{gathered}
\mathrm{q}\left\{1-\Phi(\bar{\omega}) \mu+\phi(\bar{\omega}) \mu\left[\mathrm{f}(\bar{\omega}) / \mathrm{f}^{\prime}(\bar{\omega})\right]\right\}=1 \\
\mathrm{i}=\{1 /[1-\mathrm{qg}(\bar{\omega})]\} \mathrm{n} .
\end{gathered}
$$

Equation (1) defines an implicit function $\bar{\omega}(q)$, with $\bar{\omega}$ increasing in $q$. Substituting this function into (2), we have the implicit function $i(q, n)$, which represents the amount of consumption goods placed into the capital technology. The expected capital output is then given by $\mathrm{I}^{\mathrm{S}}(\mathrm{q}, \mathrm{n}) \equiv \mathrm{i}(\mathrm{q}, \mathrm{n})\{1-\mu \Phi[\bar{\omega}(\mathrm{q})]\}$, which can be interpreted as the investment (or new-capital) supply function. Since (1) pins down $\bar{\omega}$ uniquely, the linearity of (2) implies that this supply function aggregates: aggregate investment (summing $\mathrm{I}^{\mathrm{S}}$ across all entrepreneurs) depends only on the economywide price of capital $q$ and aggregate net worth (summing $\mathrm{n}$ across all entrepreneurs). It is this aggregation result that we exploit below.

Before proceeding to the general equilibrium model, it is instructive to review some of the comparative statics of the contracting problem. It is straightforward to show that $I_{1}^{S}(q, n)>0$ and $I_{2}^{S}(q, n)>0$ (see the appendix). The positive slope to the capital supply curve $\left(\mathrm{I}_{1}^{\mathrm{S}}>0\right)$ is isomorphic to models that assume some increasing cost to adjusting the capital stock. Here, this positive slope is a natural result of the agency problem. For a given level of net worth, increases in capital production are possible only with a greater reliance on external funds, and these external funds are subject to greater agency costs. As for net worth, it can be viewed as a supply-curve shifter because increases in net worth lower agency costs and thus boost the level of capital production for a given price of capital $\left(I_{2}^{S}>0\right)$. 
Another variable that will be useful below is the expected return to internal funds. This is given by $\mathrm{qf}(\bar{\omega}) \mathrm{i} / \mathrm{n}=\mathrm{qf}(\bar{\omega}) /[1-\mathrm{qg}(\bar{\omega})]$. (Intuitively, net worth of size $\mathrm{n}$ is leveraged into a project of size $i$, entrepreneurs keep share $f(\bar{\omega})$ of the capital produced, and capital is priced at $\mathrm{q}$ consumption goods.) Because we assume that all economic rents on the contract flow to the entrepreneur, this return is strictly increasing in $\mathrm{q}$.

\section{The General Equilibrium Model}

The goal of this section is to embed the contracting problem of section 2 into an otherwise standard RBC model. The standard model assumes that new capital is created at the end of the period using consumption goods, with a nonstochastic one-to-one transformation rate (implying an investment supply curve that is perfectly elastic at unity). This newly produced capital then comes "on line" in the next period. Below, we will utilize this same timing, but replace the one-to-one transformation assumption with the contracting problem outlined in section 2 . In particular, if a household wishes to purchase capital, it must fund entrepreneurial projects, and these projects are subject to agency problems. Figure summarizes the sequence of events in a given period. We will now turn to the specifics of the model.

The model economy consists of a continuum of agents with unit mass. The agents are of two types: households (fraction 1- $\eta$ ) and entrepreneurs (fraction $\eta$ ). As discussed in the previous section, the entrepreneurs are involved in producing the investment good. Entrepreneurs receive their external financing from households via intermediaries that we will refer to as capital mutual funds (CMFs). The economy is also populated with numerous firms producing the single consumption good. We follow BG and assume that these 
consumption-producing firms are not subject to any agency problems, so that we need not be specific about how they are financed. Because their activities are somewhat standard, we will first discuss the behavior of households and firms. We will then turn to the entrepreneurs and the CMFs.

Households are infinitely lived, with preferences given by

$$
E_{0} \sum_{t=0}^{\infty} \beta^{t} U\left(c_{t}, 1-L_{t}\right) \text {, }
$$

where $E_{0}$ denotes the expectation operator conditional on time- 0 information, $\beta \in(0,1)$ is the personal discount factor, $c_{t}$ is time-t consumption, $L_{t}$ is time-t labor, and the leisure endowment is normalized to unity. In the course of any given period, households sell their labor input to consumption-producing firms at a wage rate of $w_{t}$, rent their previously accumulated capital holdings to these firms at rental rate $r_{t}$, purchase consumption from these firms at a price of unity (i.e., consumption is the numeraire), and purchase new capital goods at a price of $\mathrm{q}_{\mathrm{t}}$. Capital goods are purchased in a competitive capital market that opens at the end of the period--a market that potentially involves households purchasing capital from other households, from entrepreneurs, or from CMFs. In equilibrium, however, the capital purchases are entirely from the CMFs. Household choices are summarized in the labor supply curve

$$
\mathrm{U}_{\mathrm{L}}(\mathrm{t}) / \mathrm{U}_{\mathrm{c}}(\mathrm{t})=\mathrm{w}_{\mathrm{t}}
$$

and in the dynamic capital-demand relationship

$$
q_{t} U_{c}(t)=\beta E_{t} U_{c}(t+1)\left[q_{t+1}(1-\delta)+r_{t+1}\right]
$$

where $\delta$ is the rate of depreciation on capital. Each household also owns an equal equity share in each of the firms.

The firms in this economy produce the consumption good utilizing a standard 
constant-returns-to-scale production function. In the aggregate, this technology is given by

$$
\mathrm{Y}_{\mathrm{t}}=\theta_{\mathrm{t}} \mathrm{F}\left(\mathrm{K}_{\mathrm{t}}, \mathrm{H}_{\mathrm{t}}, \mathrm{H}_{\mathrm{t}}^{\mathrm{e}}\right)
$$

where $Y_{t}$ denotes aggregate output of the consumption good, $\theta_{t}$ denotes the stochastic productivity parameter, $\mathrm{K}_{\mathrm{t}}$ denotes the aggregate capital stock, $\mathrm{H}_{\mathrm{t}}$ denotes the aggregate supply of household labor, and $\mathrm{H}_{\mathrm{t}}^{\mathrm{e}}$ denotes the aggregate supply of entrepreneurial labor. Competition in the factor market implies that wage and rental rates are equal to their respective marginal products: $r_{t}=\theta_{t} F_{1}(t), w_{t}=\theta_{t} F_{2}(t)$, and $x_{t}=\theta_{t} F_{3}(t)$, where $x_{t}$ is the wage rate for entrepreneurial labor. The assumption of entrepreneurial labor income is necessary because it ensures that each entrepreneur always has a nonzero level of net worth. This is important because the financial contracting problem is not well defined for zero levels of net worth. Below, we will assume that this source of net worth is quite small but nonzero.

Entrepreneurs maximize the intertemporal objective

$$
E_{0} \sum_{t=0}^{\bar{T}} \beta c_{t}^{t_{t}},
$$

where $c_{t}^{e}$ denotes time-t consumption and $\bar{T}$ is the stochastic death date. The expectation is taken over the aggregate productivity shocks $\left(\theta_{\mathrm{t}}\right)$, the idiosyncratic technology shocks $\left(\omega_{t}\right)$, and the idiosyncratic lifetime of the entrepreneur $(\tilde{T})$. These three shocks are all uncorrelated with one another. There is a law of large numbers at work here, so that only the aggregate productivity shock has any aggregate consequences.

The moral hazard problem implies that the return to entrepreneurial savings is greater than the return to household savings. In the steady state, the latter is given 
by $1 / \beta$. Since the entrepreneurs have linear preferences, this implies that they will postpone consumption and accumulate capital throughout their lifetime, with the goal of a consumption binge on the eve of their death. ${ }^{6}$ This uncertain lifetime and desire to postpone consumption is discussed more fully below.

Let $\mathrm{z}_{\mathrm{t}}$ denote the capital holdings of a typical entrepreneur at the beginning of period t. To raise internal funds, the entrepreneur rents this capital and inelastically supplies his unit endowment of labor to firms. After these transactions are finished, the net worth of the entrepreneur is given by

$$
n_{t}=x_{t}+z_{t}\left[q_{t}(1-\delta)+r_{t}\right]
$$

The entrepreneur uses this net worth as the basis for the loan agreement that he will enter into with the lender. As noted in the introduction, we sidestep any repeated game aspects of the financial contract by assuming that there is enough intertemporal anonymity among entrepreneurs so that the contract can be based on entrepreneurial net worth, but not on past contractual outcomes.

Since the entrepreneurs use the borrowed funds to produce capital, the lenders in this economy are ultimately the households that wish to purchase capital. As in Diamond (1984) and Williamson (1986), there is a clear role for CMFs to intermediate these purchases between households and entrepreneurs. By providing resources to an infinite number of entrepreneurs, the CMF can ensure a certain return to the household, i.e., an expenditure of $q_{t}$ consumption goods guarantees one capital good. The law of large numbers, and the assumption that there is no aggregate uncertainty over the duration of the contract, implies that the CMF will be, as assumed in section 2 , risk neutral. The CMF is thus a type of cooperative by which capital can be efficiently purchased. A

\footnotetext{
${ }^{6}$ More precisely, this desire to postpone consumption holds for the nonstochastic
} steady state and for small perturbations around it. 
household that turns over $q_{t}$ consumption goods to the CMF receives in return one capital good. The CMF takes the funds provided to it by households and uses them to provide loans to entrepreneurs and to purchase capital from the entrepreneurs who die at the end of the period.

This leads us back to entrepreneurial lifetime. At the end of each period, fraction $\gamma$ of entrepreneurs "die," where death entails selling all of their accumulated capital to CMFs, consuming the proceeds, and exiting the economy. At the beginning of the next period, these expired entrepreneurs are replaced by new entrepreneurs (endowed with zero capital), so that the population of entrepreneurs remains fixed. If we let $Z_{t}$ denote the aggregate entrepreneurial capital stock, then we have

$$
\mathrm{Z}_{\mathrm{t}+1}=(1-\gamma) f\left(\bar{\omega}_{\mathrm{t}}\right)\left\{\eta \mathrm{x}_{\mathrm{t}}+\mathrm{Z}_{\mathrm{t}}\left[\mathrm{q}_{\mathrm{t}}(1-\delta)+\mathrm{r}_{\mathrm{t}}\right]\right\}\left\{1 /\left[1-\mathrm{q}_{\mathrm{t}} \mathrm{g}\left(\bar{\omega}_{\mathrm{t}}\right)\right]\right\}
$$

This equation is quite intuitive. The first term in braces is time-t aggregate entrepreneurial net worth. The second term in braces is the investment-to-net-worth ratio and thus represents the method by which a given level of net worth is leveraged up into a larger project size. Finally, the entrepreneur keeps share $f\left(\bar{\omega}_{t}\right)$ of the project outcome, and only fraction $(1-\gamma)$ of these entrepreneurs live on into the next period.

The previous equation also makes clear why we need to assume that entrepreneurs die. In the steady state, a unit of entrepreneurial capital is transformed into $q / \beta$ units of net worth. The financial contract then transforms this net worth back into $(q / \beta)[f /(1-q g)]>1$ units of capital. ${ }^{7} Z_{t}$ thus roughly evolves according to

This discussion also highlights the entrepreneur's desire to postpone consumption until his death. Intertemporally, one unit of consumption becomes $(1 / q)(q / \beta)=1 / \beta$ units of consumption goods in the next period. The entrepreneur then transforms this net worth into $(1 / \beta) q[f /(1-q g)]$ consumption goods at the end of the same period. Since this total return is greater than $(1 / \beta)$, the entrepreneur will always postpone his consumption. That is, the entrepreneur postpones his consumption because the internal return is greater than the opportunity cost of unity. 


$$
\mathrm{Z}_{\mathrm{t}+1}=(1-\gamma)[\mathrm{f} /(1-\mathrm{qg})](\mathrm{q} / \beta) \mathrm{Z}_{\mathrm{t}}>(1-\gamma) \mathrm{Z}_{\mathrm{t}} .
$$

Absent the death rate $\gamma$, entrepreneurs would accumulate capital until they are totally self-financed $(i=n)$ and agency costs disappear. Thus, the death rate $\gamma$ ensures that even though individual entrepreneurs would always like to accumulate more capital, in the aggregate they never actually achieve net worth levels that allow aggregate equilibrium investment to be entirely internally financed. This last statement makes clear that some assumption analogous to our death assumption is needed in agency models with long-lived entrepreneurs. Agency costs imply that the return to internal funds is greater than the return to external funds, so that absent some ad hoc assumption on behavior, entrepreneurs will quickly accumulate a large share of the capital stock. ${ }^{8}$

To close the model, we need only state the market-clearing conditions. There are four markets in this economy: two labor markets, a consumption-goods market, and a capital-goods market. The respective clearing conditions are given by

$$
\begin{gathered}
\mathrm{H}_{\mathrm{t}}=(1-\eta) \mathrm{L}_{\mathrm{t}} \\
\mathrm{H}_{\mathrm{t}}^{\mathrm{e}}=\eta \\
(1-\eta) \mathrm{c}_{\mathrm{t}}+\eta \gamma \mathrm{q}_{\mathrm{t}} \mathrm{i}_{\mathrm{t}} \mathrm{f}\left(\bar{\omega}_{\mathrm{t}}\right)+\eta \mathrm{i}_{\mathrm{t}}=\mathrm{Y}_{\mathrm{t}} \\
\mathrm{K}_{\mathrm{t}+1}=(1-\delta) \mathrm{K}_{\mathrm{t}}+\eta \mathrm{i}_{\mathrm{t}}\left[1-\Phi\left(\bar{\omega}_{\mathrm{t}}\right) \mu\right],
\end{gathered}
$$

where the consumption-goods relationship sums household consumption, entrepreneurial consumption, and aggregate investment. A recursive competitive equilibrium is defined by decision rules for $K_{t+1}, Z_{t+1}, H_{t}, a_{t}, n_{t}, i_{t}, \bar{\omega}_{t}$, and $c_{t}$, where these decision rules are 8Kiyotaki and Moore's (1995) assumption of nontradable output ("bruised fruit")
provides entrepreneurs with the incentive to accumulate capital, and their strict
borrowing constraint implies that some of the capital stock will always be held by non-
entrepreneurs in equilibrium. 
stationary functions of $\left(\mathrm{K}_{\mathrm{t}}, \mathrm{Z}_{\mathrm{t}}, \theta_{\mathrm{t}}\right)$ and satisfy the following Euler equations:

$$
\begin{gathered}
U_{L}(t) / U_{c}(t)=\theta_{t} F_{2}\left(K_{t}, H_{t}, \eta\right) \\
q_{t} U_{c}(t)=\beta E_{t} U_{c}(t+1)\left[q_{t+1}(1-\delta)+\theta_{t+1} F_{1}\left(K_{t+1}, H_{t+1}, \eta\right)\right] \\
K_{t+1}=(1-\delta) K_{t}+\eta i_{t}\left[1-\Phi\left(\bar{\omega}_{t}\right) \mu\right] \\
(1-\eta) c_{t}+\eta \gamma q_{t} i_{t} f\left(\bar{\omega}_{t}\right)+\eta i_{t}=Y_{t} \\
q_{t}=1 /\left\{1-\Phi\left(\bar{\omega}_{t}\right) \mu+\phi\left(\bar{\omega}_{t}\right) \mu\left[f\left(\bar{\omega}_{t}\right) / f^{\prime}\left(\bar{\omega}_{t}\right)\right]\right\} \\
i_{t}=\left\{1 /\left[1-q_{t} g\left(\bar{\omega}_{t}\right)\right]\right\} n_{t} \\
n_{t}=\theta_{t} F_{3}\left(K_{t}, H_{t}, \eta\right)+\left(Z_{t} / \eta\right)\left[q_{t}(1-\delta)+\theta_{t} F_{1}\left(K_{t}, H_{t}, \eta\right)\right] \\
Z_{t+1}=(1-\gamma) f\left(\bar{\omega}_{t}\right) \eta i_{t} .
\end{gathered}
$$

In the appendix, we demonstrate that if we hold net worth constant, then equilibrium conditions (3)-(8) are isomorphic to a standard RBC model with costs of adjusting the capital stock. ${ }^{9}$ It is in this sense that the agency-cost model can be seen as a particular way of endogenizing adjustment costs. One unique characteristic of these adjustment costs is that they are affected by the level of net worth--Increases in net worth lower agency costs and thus make it easier to expand the capital stock. The remaining two Euler equations (9)-(10) track the dynamic behavior of this net worth

\footnotetext{
${ }^{9}$ There are a few inconsequential differences between this model with net worth held constant and an adjustment-cost model (such as entrepreneurial labor and entrepreneurial capital). With $\mu=0$, (7) implies that $\mathrm{q}=1$, so that the model further collapses to the standard RBC model with no adjustment costs.
} 
variable.

\section{Calibration}

The model is parameterized at the nonstochastic steady state to roughly match empirical counterparts.

Household preferences are given by $\mathrm{U}(\mathrm{c}, 1-\mathrm{L})=\ln (\mathrm{c})+v(1-\mathrm{L})$, where the constant $v$ is set equal to 2.807 , so that $L=.3$. We set $\beta=.99$, thus implying a 4 percent annual real rate of interest. The value of $\eta$ is simply a normalization.

The consumption production technology is assumed to be Cobb-Douglas with a capital share of .36 , a household labor share of .6399 , and an entrepreneurial labor share of .0001 . Recall that this last share needs to be positive to ensure that each entrepreneur always has at least some net worth. We set it arbitrarily small so that the model with $\mu$ $=0$ essentially collapses to the standard RBC model. The capital depreciation rate is set to $\delta=.02$.

As for the monitoring technology, there is a great deal of controversy within the empirical literature on this number. One perspective is that it should entail only the direct costs of bankruptcy. For example, Warner (1977) examines the railroad industry and comes up with a bankruptcy cost estimate of about 4 percent. However, in our view, this parameter should also include indirect costs of financial distress, such as lost sales and lost profits, because these costs can be viewed as deadweight losses from keeping capital idle for some period of time. One study that includes indirect costs estimates the sum of direct and indirect bankruptcy costs at about 20 percent of total firm assets (Altman [1984]).

In our model, bankruptcy can be viewed as the entrepreneur being closed and his 
assets being liquidated. This suggests that another measure of bankruptcy costs could be obtained by comparing the value of the firm as a going concern with the liquidation value of the firm (absent any other direct or indirect costs of bankruptcy). Using data from Chapter 11 proceedings, Alderson and Betker (1995) estimate the internal and external value of the firm (where the former is the firm's value as a going concern, and the latter is the value if its assets were liquidated). Using these estimates, they calculate that liquidation costs are equal to approximately 36 percent of firm assets.

Because of our uncertainty about which measure of agency costs is more appropriate, we provide some sensitivity analysis by presenting results for $\mu=.2$ and $\mu=.3$. We use $\mu=.3$ instead of Alderson and Betker's .36 because the authors admit that, since the figure was calculated by investment bankers hired by the firm in Chapter 11, it is probably an overestimate.

As for the distribution $\Phi$, we assume that it is lognormal with a mean of unity and a standard deviation of $\sigma$. An important characteristic of this distribution is that the bankruptcy probability, $\Phi$, is convex in the loan repayment rate, $\bar{\omega}$. In contrast, Fuerst (1995) assumes that $\Phi$ is uniform, implying that $\Phi$ is linear in $\bar{\omega}$. Our assumption of convexity is important: Since both the entrepreneur and CMF wish to avoid costly bankruptcy, this implies that the greater is the convexity of $\Phi$, the less will $\bar{\omega}$ vary in response to shocks.

We are thus left with two parameters: $\sigma$ and $\gamma$. We choose these to uniquely match two measures of default risk. The first is the model's bankruptcy rate, $\Phi\left(\bar{\omega}_{t}\right)$. The second is the model's risk premium, which we set to match the risk premium in the data. Since a loan of one consumption good implies a risky return of $1+r_{t}^{k}$ capital goods, or $q_{t}\left(1+r_{t}^{k}\right)$ consumption goods, the model's risk premium is given by $\left[q_{t}\left(1+r_{t}^{k}\right)-1\right]$.

Fisher (1994) reports a quarterly bankruptcy rate of .974 percent (using the Dun \& 
Bradstreet data set for 1984-1990), and an average annual risk premium of 157 basis points (measured as the average spread between the commercial bank lending rate and the commercial paper rate from 1967-1988). Matching these two empirical measures provides the last two identifying restrictions. For example, for $\mu=.2$, we set $\sigma=.211$ and $\gamma=$ .053. These imply an internal financing percentage of $n / i=39.0$ percent. For a higher $\mu$, we need to decrease $\sigma$ to match the risk premium, and to increase $\gamma$ to match the default rate. Hence, for $\mu=.3$, we set $\sigma=.088$ and $\gamma=.122$. These imply $n / i=17.2$ percent.

\section{Simulation}

We are now ready to turn to a numerical analysis of the model. The methods are familiar. The equilibrium conditions (3)-(10) are linearized about the steady state, and linear decision rules are then computed using the method of undetermined coefficients.

Figures 2 through 4 report the results of two experiments for the two values of bankruptcy costs $(\mu=.2$ and $\mu=.3$ ). For both sets of experiments, we compute the impulse responses for the model with agency costs $(\mu>0)$ and for a model without agency costs $(\mu=0)$. The latter is essentially the standard RBC model. ${ }^{10}$ The steady states of the two models differ, since the capital stock is slightly higher in the RBC model than in the agency-cost model. For this reason, we report the behavior of all variables relative to their steady-state values.

${ }^{10}$ The presence of entrepreneurs does alter the RBC model slightly. First, entrepreneurs receive a small wage and capital income. Second, shocks to entrepreneurial capital and hence to household wealth can potentially affect RBC dynamics. However, entrepreneurial capital and the entrepreneurial labor share are so small that the difference between our model with $\mu=0$ and the RBC model of say, King, Plosser, and Rebelo (1988), is almost imperceptible. 
5a. A Wealth Shock

The first experiment we consider is a one-time shock to the distribution of wealth in the two economies. This shock will be a one-time transfer of capital from households (lenders) to entrepreneurs (borrowers). This experiment is useful for considering the effects of various shocks to the economy that might redistribute wealth from households to entrepreneurs. For example, in Irving Fisher's debt-deflation story, surprise increases in the price level shift wealth from lenders to borrowers. Another shock might be the standard productivity shock in RBC models. (The next section will consider the effect of such a productivity shock.) Since productivity shocks will also (indirectly) cause a wealth redistribution, it is instructive to examine a pure wealth shock in order to help understand the second, more complicated experiment.

Figure 2 presents the economy's response to a one-time redistribution of capital from households to entrepreneurs. The redistribution is such that aggregate entrepreneurial net worth increases by .01 in period five. In both cases, this amounts to a redistribution of approximately .1 percent of steady-state capital. ${ }^{11}$ This trivial reduction in household capital is actually a relatively large increase in entrepreneurial net worth. For the $\mu=.2$ case, net worth increases by 14 percent, while in the $\mu=.3$ case, it increases by 29 percent.

In the frictionless RBC model, the source of investment financing is irrelevant, so that the decline in the need for external finance has no effect on the aggregate economy. As for direct wealth effects, they are so small as to be imperceptible. Hence, we do not report the RBC model.

Matters are much different in the economy with agency costs. Here, increases in

"The wealth redistribution is equal to .0986 percent of capital for the $\mu=.2$ case, and to .0989 percent for the $\mu=.3$ case. 
entrepreneurial net worth lower the need for external financing and thus reduce the agency costs of investment. This increase in net worth shifts the investment supply curve to the right (as discussed in section 2), thus boosting investment and lowering the equilibrium price of capital. This increased investment entails lower household consumption, which in turn motivates households to increase their labor input, which raises output. For the $\mu=.3(\mu=.2)$ case, investment increases by 12.1 percent $(6.3$ percent), consumption declines by 1.14 percent (.60 percent), labor increases by 3.2 percent (1.7 percent), and output increases by 1.75 percent (.9 percent). Notice that when agency costs are relatively large $(\mu=.3)$, the percentage changes in these macroeconomic variables are nearly twice that of the lower agency-cost case $(\mu=.2){ }^{12}$ After the initial shock, the economy slowly returns to the steady state as entrepreneurial deaths and bankruptcies return entrepreneurial capital to its steadystate value.

One prediction of the model that is potentially counterfactual is the decline in aggregate consumption following a wealth shock. Although the figures refer to household consumption and not aggregate consumption (household plus entrepreneurial consumption), aggregate consumption behaves similarly. This is because while entrepreneurial consumption is procyclical, it is only 1.5 percent (for $\mu=.3$ ) of aggregate consumption.

This is not a monetary economy, and we present no theory for why loan contracts

\footnotetext{
${ }^{12}$ The conclusion that the effects of a wealth shock are nearly twice as large in the $\mu=.3$ case is sensitive to the nature of the shocks being considered. If we considered a shock such that net worth increased by 10 percent in both economies, the implications would be almost identical in either economy. The reason, of course, is that steady-state net worth is slightly more than twice as large in the case with low monitoring costs. The decision to model the shock as an absolute (versus percentage) change in net worth was arbitrary. However, we chose this convention because we believe that most potential shocks to the economy would come closer to redistributing an absolute amount of net worth (and hence a given fraction of total capital) versus a given percentage change in net worth.
} 
would not be nominally indexed. However, it is instructive to translate how surprise inflation (price) shocks translate into wealth shocks, and hence output shocks, in a nonindexed economy. The typical loan size is (i-n), so that if loans were nominal and nonindexed, a one-time surprise inflation of 1 percent annually (.25 percent quarterly) would correspond to an increase in aggregate net worth of $(.0025) \eta(i-n)[q(1-\delta)+r]$. For the $\mu=.2$ case, net worth increases by .0003 , while for the $\mu=.3$ case, it increases by .0004. Hence, for the case of large monitoring costs, a one-time surprise annual inflation of 1 percent will lead to an increase in investment of .5 percent and an increase in output of .07 percent. The dynamics after such a shock would be identical (though scaled down) to those shown in figure 2. Thus, although this is a one-time shock to prices, output remains above trend for several quarters as entrepreneurial capital takes time to return to its steady state.

5b. A Productivity Shock

The second experiment we consider is a shock to aggregate productivity. To be precise, the technology process is assumed to follow

$$
\theta_{t}=(1-\rho)+\rho \theta_{t-1}+v_{t}
$$

where $v_{t}$ is a serially uncorrelated shock, $\rho$ is the autocorrelation coefficient, and the nonstochastic steady state of $\theta$ is unity. Following the typical RBC calibration methodology, we set $\rho=.95$. The shock is $v=.01$. Although this is a one-time shock, because technology is autocorrelated, productivity will stay above trend for several quarters.

The results for the low- and high-agency-cost cases are presented in figures 3 and 4 , respectively. Each figure contains the dynamics of three different models. The first 
model sets agency costs to zero and is thus the standard RBC model. The second model holds net worth in the relevant agency-cost model constant and is thus isomorphic to a standard cost-of-adjustment model (see the appendix). The third model is an economy with agency costs.

The RBC dynamics are familiar. There is a spike in investment, hours, and output as productivity increases, then each series slowly returns to normal as productivity starts declining back to its steady state. As Cogley and Nason $(1993,1995)$ demonstrate, the dynamics of investment, hours, and output are all inherited from the autocorrelation structure of the technology shock. Capital adds little propagation to these variables in and of itself.

The cost-of-adjustment model resembles the $\mathrm{RBC}$ model except that the initial impulse for investment, hours, and output is muted. Initial investment increases by much less as the rise in the price of capital serves to choke off investment demand. This muted response of investment amplifies the initial increase in consumption. The increase in consumption shifts back the labor supply curve, thus muting the responses of both hours and output. After the initial impulse, investment, hours, and output all start returning to their steady state. The dynamics closely resemble those of the RBC model, with a little added persistence.

In the agency-cost model, the dynamics in the early periods are quite different because of the behavior of net worth. On impact, net worth increases slightly as the technology shock boosts entrepreneurs' wage and rental income. However, entrepreneurial capital is initially fixed, limiting net worth's rise. Subsequently, the share of entrepreneurial capital picks up rapidly as the increased demand for capital pushes up the price of capital, thus sharply driving up the return to internal funds $[q f /(1-q g)] .{ }^{13}$

\footnotetext{
${ }^{13}$ Recall from section 2 that this return is increasing in the price of capital.
} 
Mirroring the price of capital, this return stays high for several quarters after the shock, leading to a hump-shaped path for entrepreneurial capital and thus net worth. For $\mu=.3(\mu=.2)$, entrepreneurial net worth peaks after six (ten) quarters at a value of 4.5 percent ( 3.5 percent) above steady state.

To see the importance that net worth plays in the dynamics of the agency-cost model, compare the impulse response functions for the agency-cost model and the adjustment-cost model. For the case of $\mu=.3$, three quarters after the initial productivity increase, investment is 4.7 percent above steady state with variable net worth, but only 3.4 percent above steady state when net worth is held constant. Similarly, output is 1.64 percent above normal with variable net worth, but only 1.45 percent above normal for constant net worth.

The important difference between the agency-cost model and either the adjustmentcost or the standard RBC model is the hump-shaped response function for investment. The hump shape in investment leads to a "reverse hump" in consumption after its initial increase. The decline in consumption (after its initial increase) raises household labor supply, which, when coupled with the increase in labor demand (due to the technology shock), results in a hump-shaped response for hours worked. For the model with large monitoring costs, this hump is pronounced enough to lead to a hump shape in output as well.

To better understand the model's investment behavior, figure 5 presents a supply/demand analysis of the market for investment goods (or new capital). ${ }^{14}$ Initially,

${ }^{14}$ The demand curve for household capital is given by taking a linear approximation of equation (4), where future consumption is set to its steady-state value and current consumption is given by subtracting investment demand from household income. The supply curve is given by taking a linear approximation of

$$
\eta I^{S}(q, n)-\left[Z_{t+1}-(1-\delta) Z_{t}\right]
$$

where the second term is deducted because it represents the entrepreneurs' net capital acquisitions (which are not handled through the CMF). 
$(t=0)$, the economy is in the steady state. At $t=1$, the technology shock shifts out the investment demand curve. Subsequently, investment demand starts moving slowly back to normal as time progresses. This movement is largely driven by the autocorrelation coefficient, $\rho .{ }^{15}$ The productivity shock increases the return to internal funds, thereby causing entrepreneurial capital and hence net worth to rise. By boosting entrepreneurial net worth, the productivity shock shifts the investment supply function to the right. This continues for several periods as net worth continues to grow. It is this dynamic behavior that generates the hump in the investment response and that can lead to a similar hump in hours and output. This does not occur in either the standard RBC model (where the supply curve is completely elastic at unity) or a cost-of-adjustment model (where the supply curve remains stationary). ${ }^{16}$

The model's hump-shaped impulse response is of particular interest given the recent work of Cogley and Nason (1995). Their study documents that 1) a hump-shaped response of output to a transient shock is consistent with U.S. time series, and 2) standard RBC models are unable to deliver their hump-shaped behavior (a notable exception is the labor-hoarding model of Burnside, Eichenbaum, and Rebelo [1993]). In the agency-cost model, this hump shape is a natural outcome of the dynamic behavior of net worth in

${ }^{15}$ In equilibrium, the investment demand curve actually remains nearly stationary for several quarters following the initial shock, as the decline in tomorrow's consumption increases investment demand next quarter. It shifts back in figure 5 because future consumption is set to its steady state.

${ }^{16}$ In the adjustment-cost model, the supply curve remains stationary when adjustment costs are assumed to be a function of investment only. If instead these costs depend on the investment-capital ratio, then the supply curve also shifts out as capital begins to grow. This, however, does not lead to a hump-shaped investment response, since households internalize the effect and increase their initial investment in anticipation. With agency costs, investment supply shifts out as net worth grows, but since net worth is exogenous from the household's standpoint, this shift is not internalized. 
response to a technology shock.

\section{Sensitivity Analysis}

To better understand the model, it is important to conduct some sensitivity analysis. The above discussion suggests a convenient way of characterizing the model's outcome. The power of agency costs in this model can be conveniently captured by analyzing the investment supply function. In particular, in table 1, we conduct sensitivity analysis on 1) the size of the supply curve shift (given the price of capital) in response to a shock to the entrepreneur's net worth, and 2) the magnitude of the net worth change in response to a technology shock.

To be consistent with our impulse response functions, we report the semi-elasticity of investment supply tomorrow with respect to a change in net worth, and the semielasticity of net worth tomorrow with respect to a change in technology today. In addition, we report the total effect, that is, the elasticity of tomorrow's investment supply with respect to a shock to today's technology.

The first two rows are the two calibrated experiments with low and high agency costs. These elasticities show what our previous impulse response functions indicated. A given change in net worth has a much larger effect on investment supply for large agency costs (a semi-elasticity of 24.8) versus small agency costs (a semi-elasticity of 8.1). ${ }^{17}$ The other important ingredient needed to understand the technology-shock case is how much net worth increases with respect to a percentage change in technology. This is actually slightly higher with small agency costs, indicating that the important

17 The response of investment with large agency costs is three times bigger than with small agency costs. In equilibrium, figure 5 illustrated that the effect was just under twice as big. The difference is that table 1 takes the price of capital as a given, and in equilibrium, the price of capital rises more with large agency costs to help choke off the increase in investment. 
difference between the two simulations is the effect of net worth on investment supply.

The third row illustrates the importance that the size of monitoring costs has on the model, everything else held constant. That is, we report the results for $\mu=.2$ given the distribution obtained when calibrating for $\mu=.3$. Lowering monitoring costs alone has little effect. Investment supply's response to a change in net worth falls slightly, from 24.8 to 23.5 . Similarly, the response of net worth to technology is slightly smaller (.069 versus .061). The total change in investment supply in response to a technology shock declines from 1.71 to 1.44 . This is in sharp contrast to the calibrated $\mu=.2$ case, where the comparable elasticity is $.77 . .^{18}$

Notice that the only parameter which is different between the two $\mu=.2$ experiments is that the noncalibrated low-monitoring-cost experiment has a smaller variance. Thus, the large differences between the two calibrated economies is not the difference in monitoring costs, per se, but the increased standard deviation of $\omega$ that is necessary to match the economy's risk premium when monitoring costs are small. The risk premium in the calibrated economy falls from 157 basis points to 108 basis points for the low-monitoring-cost, noncalibrated economy. Therefore, this analysis also illustrates the significant role that the risk premium plays in our calibration exercise.

Row 4 of the table shows the importance that the estimated bankruptcy rate of .974 percent has on our calibration by demonstrating the effect of calibrating to a higher bankruptcy rate of 1.5 percent. Although monitoring costs are assumed to be relatively

${ }^{18}$ If monitoring costs were zero, investment would be perfectly elastic at unity so that changes in net worth would have no effect on investment supply. This elasticity increases, everything else held constant, as monitoring costs decline. Therefore, the difference between the calibrated $\mu=.3$ experiment and the noncalibrated $\mu=.2$ experiment will be a little larger than indicated by the semi-elasticity of investment with respect to net worth. Similarly, when calibrating for $\mu=.2$, the increased variance of $\omega$ causes the price elasticity to decline, so that the effect between the two calibrated agency-cost experiments is a little closer than indicated. 
small $(\mu=.2)$, the dynamic effects of agency costs are larger now than when agency costs were high $(\mu=.3)$ but the bankruptcy rate was .974 percent. A one percent change in productivity will have a 1.9 percent change in investment supply next period. This is in contrast to the 1.7 percent change that occurs when we calibrate with high monitoring costs. ${ }^{19}$ This apparent effect is muted somewhat by the increased price elasticity of investment supply when bankruptcy probabilities are high.

Perusing table 1 indicates that a statistic which appears to be useful for predicting the dynamic effects of agency costs is the internal financing ratio, defined as net worth divided by investment. The larger the share of investment that is financed internally, the smaller is the impact of agency costs on the economy. This, of course, makes intuitive sense: A firm that is entirely internally financed would suffer no agency costs, since no moral hazard problems would arise. This relationship is especially tight given the linearity of investment with respect to net worth.

From equation (2), the internal financing percentage in the model is simply [1$\mathrm{qg}(\bar{\omega})]$. Therefore, the higher the fraction of net capital output that goes to the lender $[g(\bar{\omega})]$, the lower is the fraction of investment that is financed internally and the bigger is the impact that agency costs will have on the dynamics of the model. From the definition of $f(\bar{\omega})$, the fraction of net capital output that goes to the entrepreneur, given both the distribution of $\omega$ and the probability of bankruptcy, is not affected by monitoring costs $(\mu)$. Therefore, the parameter $\mu$ affects $g(\bar{\omega})$ only to the extent that $\mu$ changes expected monitoring costs. Because the probability of bankruptcy is so small,

\footnotetext{
${ }^{19}$ In fact, the hump in output for the model with low agency costs and high bankruptcy probabilities is more pronounced than in our calibrated economy with high agency costs. There is reason to believe that our estimated bankruptcy probability is on the low side, since the estimated sample does not include nonincorporated businesses (either individually owned or partnerships). These companies tend to have much larger bankruptcy probabilities.
} 
changing monitoring costs alone has a relatively minor impact on the dynamics of the model.

Yet the more uncertain the shock in the investment production process, the larger is the fraction of net capital output entrepreneurs must (on average) receive. This is due to the option value of the optimal debt contract for entrepreneurs. Entrepreneurs' expected return increases as the variance of $\omega$ rises. A higher return leads to a larger steady-state level of net worth and to a reduced need for external finance. This explains why increasing the variance lowers the impact of agency costs.

The model appears to suggest that countries with a larger share of internally financed investment would be less affected by agency costs. In contrast, differences in the risk premium may be an extremely poor indicator of the impact of agency costs, since the risk premium is positively related to the variance of the shock process.

Aggregate measures of internal financing, however, may not indicate the importance of agency costs. We could have calibrated the model by matching an empirical measure of the internal financing percentage. We chose not to follow this route because the model makes no clear prediction on this percentage. Remember, there are two different types of firms in our model--investment firms and consumption-producing firms. Although there is a clear prediction for this ratio for the investment firms, the form of capital financing for the consumption-producing firms is indeterminate. This indeterminacy is just the Modigliani-Miller theorem. 


\section{Conclusion}

The principal contribution of this paper is to demonstrate a tractable way of modeling and quantifying the role of agency costs in the business cycle. Two quantitative conclusions warrant restatement. First, debt-deflations can have a significant and persistent effect on real activity. In the case of large monitoring costs, a relatively small wealth redistribution (corresponding to an annual 1.0 percent surprise inflation) leads to a 0.5 percent increase in investment spending. Second, the agency-cost model naturally delivers a hump-shaped investment response to a productivity shock. This is because households delay investment decisions until agency costs are at their lowest--a point in time several periods after the initial shock.

Another contribution of the paper is to demonstrate the linkages between explicit models of agency costs and adjustment-cost models which assume that there are increasing costs to producing capital. Holding net worth fixed, this paper's agency-cost model closely resembles an adjustment-cost model in that both deliver an upwardly sloped capital supply curve. The paper thus delivers an endogenous model of capital adjustment costs. As part of this endogeneity, the model also demonstrates how the capital supply curve is shifted by movements in entrepreneurial net worth.

There are several natural extensions of the current work. First, the model is easily amenable to considering other shocks to the economy. For example, Fisher (1994) and Fuerst $(1994,1995)$ examine the effect of monetary shocks in related agency-cost models. Similarly, Williamson (1987b) considers shocks to the variance of the entrepreneur's technology in an overlapping generations model. Second, a wide variety of assumptions can deliver differing models of agency costs. In this paper, agency costs arise in the creation of new capital and thus affect the investment supply curve. One obvious alternative is to construct a model in which agency costs arise in the 
consumption sector, and thus affect the investment demand curve. Finally, several authors have stressed that only a subset of firms are constrained by agency issues, while many other firms are so large that these agency issues are relatively unimportant (for a recent survey and discussion, see Bernanke, Gertler, and Gilchrist [1994]). An interesting extension of this work would be to construct a model that captures these types of asymmetries. 


\section{APPENDIX}

In this appendix, we demonstrate how the agency-cost model developed in the paper is isomorphic to a model in which there are costs to adjusting the capital stock. A standard cost-of-adjustment model (Hayashi [1982]) assumes that capital evolves according to

$$
\mathrm{K}_{\mathrm{t}+1}=(1-\delta) \mathrm{K}_{\mathrm{t}}+\psi\left(\mathrm{I}_{\mathrm{t}}\right)
$$

where $\psi>0$ is increasing and concave. Maximizing lifetime utility subject to this constraint yields

$$
\begin{gathered}
q_{t} U_{c}(t)=\beta E_{t} U_{c}(t+1)\left[q_{t+1}(1-\delta)+\theta_{t+1} F_{1}\left(K_{t+1}, H_{t+1}\right)\right] \\
q_{t}=1 / \psi^{\prime}\left(I_{t}\right),
\end{gathered}
$$

where $q_{t}$ corresponds to the price of installed capital (or Tobin's $q$ ). Equation (A1) corresponds to equation (4) in the agency-cost model. Equation (A2) represents the supply curve for newly installed capital, $I_{t} \equiv S\left(q_{t}\right)$, with $d S / d q_{t}>0$. In the agencycost model, we have a supply curve for new capital given by $\mathrm{I}^{\mathrm{s}}\left(\mathrm{q}_{\mathrm{t}}, \mathrm{n}_{\mathrm{t}}\right) \equiv \mathrm{i}\left(\mathrm{q}_{\mathrm{t}}, \mathrm{n}_{\mathrm{t}}\right)\{1$ $\left.\mu \Phi\left[\bar{\omega}\left(\mathrm{q}_{\mathfrak{t}}\right)\right]\right\}$. Analogous to the adjustment-cost model, we have $\mathrm{I}_{1}^{\mathrm{S}}>0$. In contrast to the adjustment-cost model, we also have that the supply curve is shifted by net worth. Specifically, increases in net worth shift the supply curve to the right, $I_{2}^{S}>0$. This effect is a central issue in the agency-cost model. Note in particular that if net worth is held constant, the agency-cost model is isomorphic to the adjustment-cost model.

It is a straightforward application of comparative statics to show that $I_{1}^{S}>0$ and $\mathrm{I}_{2}^{\mathrm{S}}>0$. Define the Lagrangean 


$$
\mathrm{L}(\mathrm{i}, \bar{\omega}, \lambda) \equiv \mathrm{qif}(\bar{\omega})+\lambda[\mathrm{qig}(\bar{\omega})-\mathrm{i}+\mathrm{n}] .
$$

We then have the following comparative statics:

$$
\begin{gathered}
\mathrm{di} / \mathrm{dq}=\left[\mathrm{igL}_{\omega \omega} \mathrm{L}_{\mathrm{i} \lambda}+\mathrm{L}_{\omega \lambda}^{2}(\mathrm{f}+\lambda \mathrm{g})\right] / \Delta>0 \\
\mathrm{~d} \bar{\omega} / \mathrm{dq}=-(\mathrm{f}+\lambda \mathrm{g}) \mathrm{L}_{\omega \lambda} \mathrm{L}_{\mathrm{i} \lambda} / \Delta>0 \\
\mathrm{di} / \mathrm{dn}=\mathrm{L}_{\omega \omega} \mathrm{L}_{\mathrm{i} \lambda} / \Delta>0 \\
\mathrm{~d} \bar{\omega} / \mathrm{dn}=0,
\end{gathered}
$$

where $\Delta \equiv-\mathrm{L}_{\mathrm{i} \lambda}^{2} \mathrm{~L}_{\omega \omega}>0$ is the second-order condition. Since $\bar{\omega}$ does not vary with $\mathrm{n}$, it is now obvious that $I_{2}^{S}>0$. As for $I_{1}^{S}$, the optimal contract also maximizes if $(\bar{\omega})=\mathrm{i}[1-$ $\Phi(\bar{\omega}) \mu-\mathrm{g}(\bar{\omega})]$. An increase in $\mathrm{q}$ relaxes the constraint on the lender's return, so that if $(\bar{\omega})$ must be increasing in $\mathrm{q}$. Since $\operatorname{ig}(\bar{\omega})$ is increasing in $\mathrm{q}$, we then have that $\mathrm{i}[1-$ $\Phi(\bar{\omega}) \mu] \equiv I^{S}$ is also increasing in $q$. 


\section{REFERENCES}

Alderson, Michael J., and Brian L. Betker, "Liquidation Costs and Capital Structure," mimeo, 1995.

Altman, Edward I., "A Further Investigation of the Bankruptcy Cost Question," Journal of Finance (39), September 1984, 1067-1089.

Bernanke, Ben, "Nonmonetary Effects of the Financial Crisis in the Propagation of the Great Depression," American Economic Review (73), June 1983, 257-276.

, and Mark Gertler, "Agency Costs, Net Worth, and Business Fluctuations," American Economic Review (79), 1989, 14-31.

the Flight to Quality,"

Boyd, John H., and Bruce D. Smith, "How Good Are Standard Debt Contracts? Stochastic versus Nonstochastic Monitoring in a Costly State Verification Environment," Journal of Business (67), 1994, 539-561.

Burnside, Craig, Martin Eichenbaum, and Sergio Rebelo, "Labor Hoarding and the Business Cycle," Journal of Political Economy (101), 1993, 245-273.

Cogley, Timothy, and James M. Nason, "Impulse Dynamics and Propagation Mechanisms in a Real Business Cycle Model," Economic Letters (43), 1993, 77-81.

Models," American Economic Review (85), June 1995, 492-511.

, and $\quad$ "Output Dynamics in Real-Business-Cycle

Diamond, Douglas, "Financial Intermediation and Delegated Monitoring," Review of Economic Studies (51), 1984, 393-414.

Diamond, Peter A., "Government Debt in a Neoclassical Growth Model," American Economic Review (55), 1965, 1126-1150.

Fisher, Irving, "The Debt-Deflation Theory of Great Depressions," Econometrica (1), October 1933, 337-357.

Fisher, Jonas D.M., "Credit Market Imperfections and the Heterogeneous Response of Firms to Monetary Shocks," University of Western Ontario, working paper, May 1994.

Fuerst, Timothy S., "The Availability Doctrine," Journal of Monetary Economics (34), 1994, 429-444.

, "Monetary and Financial Interactions in the Business Cycle," Journal of Money, Credit, and Banking (27), 1995, 1321-1338. 
Gale, Douglas, and Martin Hellwig, "Incentive-Compatible Debt Contracts I: The One-Period Problem," Review of Economic Studies (52), 1985, 647-664.

Gertler, Mark, "Financial Capacity and Output Fluctuations in an Economy with Multi-Period Financial Relationships," Review of Economic Studies (59), 1992, 455-472.

Cycle," Journal of Money, Credit, and Banking (27), 1995, 1342-1353.

Hart, Oliver, and John Moore, "A Theory of Debt Based on the Inalienability of Human Capital," Quarterly Journal of Economics, 1994, 841-879.

Hayashi, Fumio, "Tobin's Marginal q and Average q: A Neoclassical Interpretation," Econometrica (50), 1982, 213-224.

King, Robert G., Charles I. Plosser, and Sergio T. Rebelo, "Production, Growth, and Business Cycles: I. The Basic Neoclassical Model," Journal of Monetary Economics (21), 1988, 195-232.

Kiyotaki, Nobuhiro, and John H. Moore, "Credit Cycles," NBER Working Paper No. 5083, April 1995.

Prescott, Edward, "Theory ahead of Business Cycle Measurement," Federal Reserve Bank of Minneapolis, Quarterly Review, Fall 1986.

, and Robert Townsend, "Pareto Optima and Competitive Equilibria with Adverse Selection and Moral Hazard," Econometrica (52), 1984, $21-45$.

Townsend, Robert M., "Optimal Contracts and Competitive Markets with Costly State Verification," Journal of Economic Theory (21), 1979, 265-293. $337-348$.

Warner, Jerald, "Bankruptcy Costs: Some Evidence," Journal of Finance (32), 1977,

Williamson, Stephen, "Costly Monitoring, Financial Intermediation, and Equilibrium Credit Rationing," Journal of Monetary Economics (18), 1986, 159-179.

Rationing," Quarterly Journal of Economics (102), 1987a, 135-145.

"Costly Monitoring, Optimal Contracts, and Equilibrium Credit

"Financial Intermediation, Business Failures, and Real Business Cycles," Journal of Political Economy (95), 1987b, 1196-1216. 


\section{FIGURE 1:}

\section{The Sequence of Events in a Given Time Period}

1. The current aggregate productivity shock is realized $\left(\theta_{t}\right)$.

2. Firms hire labor and rent capital from households and entrepreneurs. These inputs are used to produce the consumption good, $\mathrm{Y}_{\mathrm{t}}=\theta_{\mathrm{t}} \mathrm{F}\left(\mathrm{K}_{\mathrm{t}}, \mathrm{H}_{\mathrm{t}}, \mathrm{H}_{\mathrm{t}}^{\mathrm{e}}\right)$.

3. Households decide how much of their labor and capital income to consume immediately, and how much to use to purchase the investment good. For each unit of investment that the household wishes to purchase, it gives $q_{t}$ consumption goods to the capital mutual fund $(\mathrm{CMF})$.

4. The CMFs use the resources obtained from households to provide loans to an infinite number of entrepreneurs utilizing the optimal financial contract derived in section 2 .

5. Entrepreneurs borrow resources from the CMF and place the resources into their capital-creation technology.

6. The idiosyncratic technology shock of each entrepreneur is realized, $\omega^{j}$, where $j$ indexes the infinite number of entrepreneurs. If $\omega^{j} \geq \bar{\omega}$, the loan from the CMF is repaid; otherwise, the entrepreneur declares bankruptcy and is monitored by the CMF.

7. Fraction $\gamma$ of the entrepreneurs receive news that they are to die. They sell their capital holdings (if any) to the CMF, consume the proceeds, and exit the economy. At the beginning of the next period, a new batch of entrepreneurs is born that will replace those who have expired. 
Figure 2: Wealth Shock

Entrepreneurial net worth

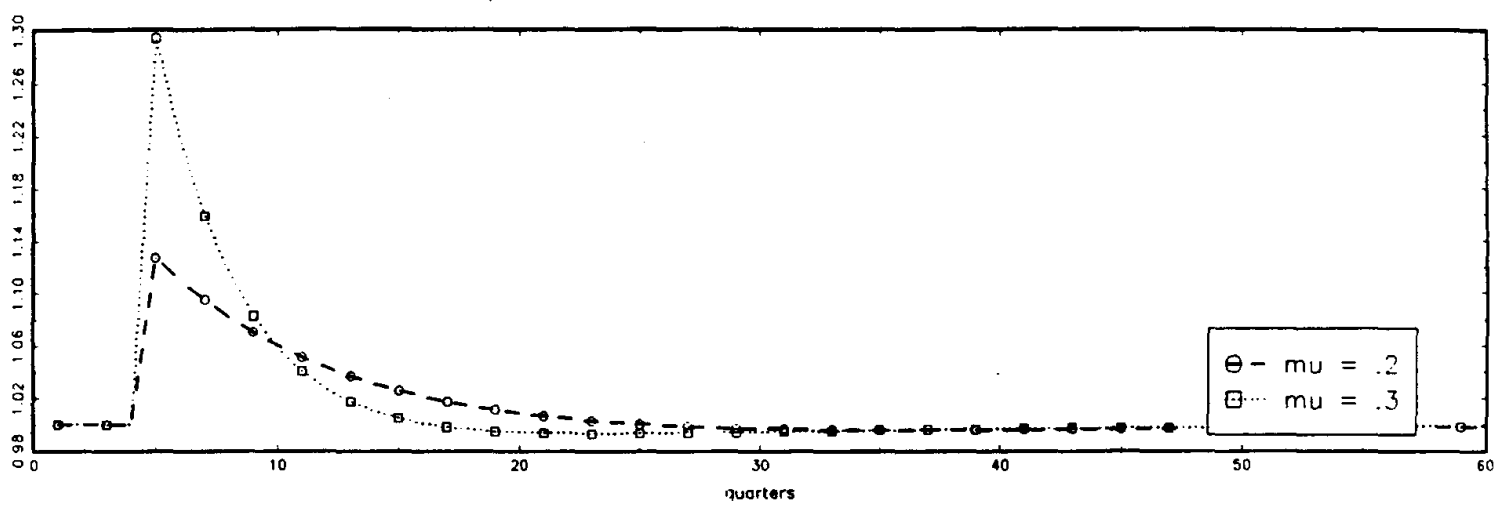

Investment

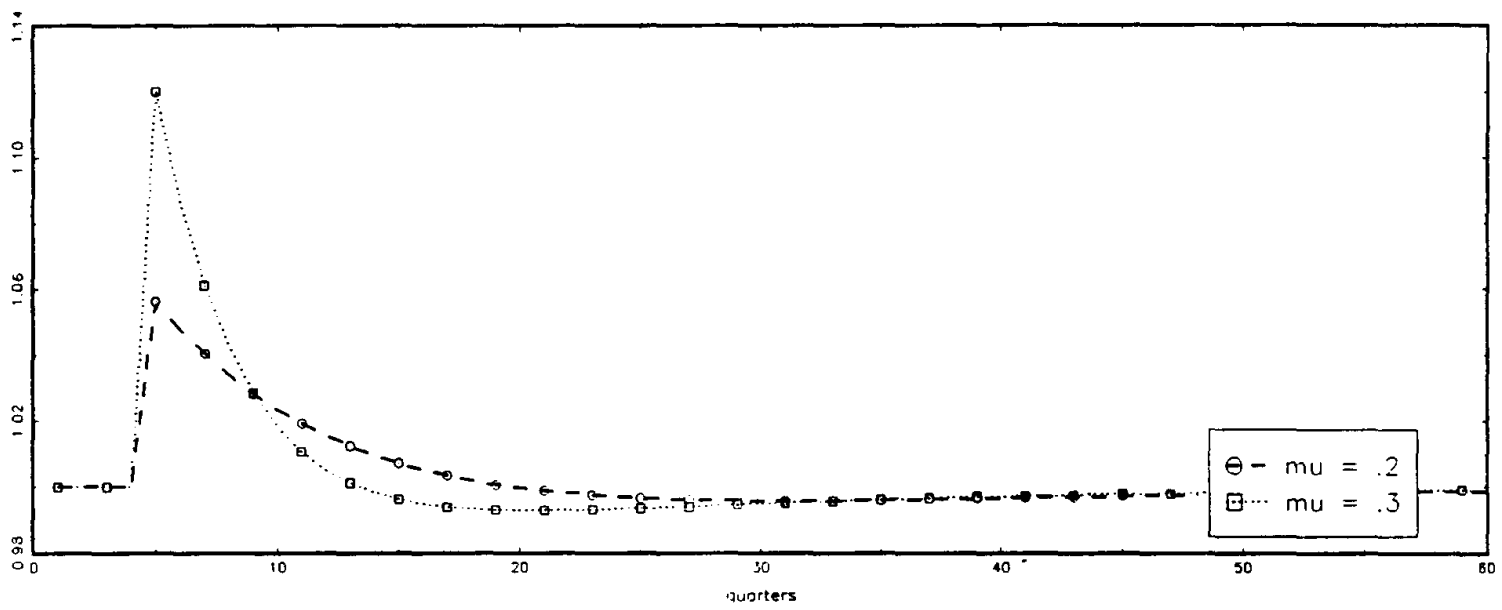

Price of capital

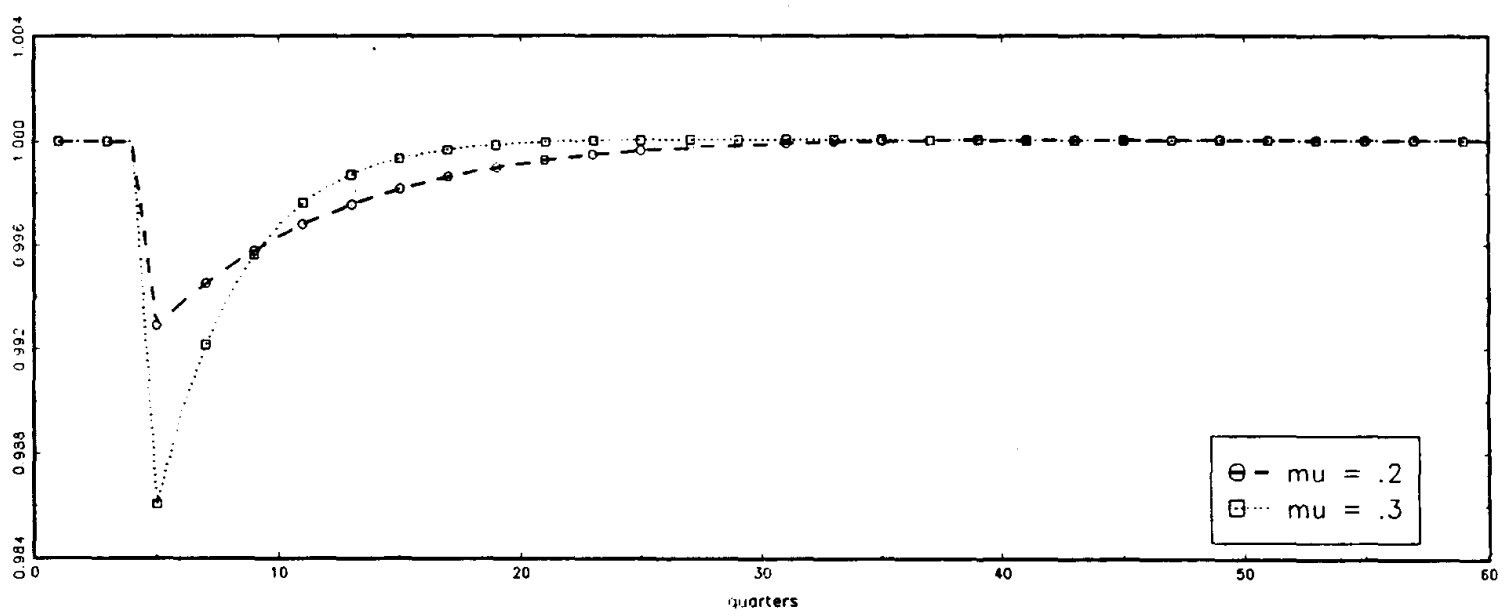


Figure 2: (cont.)

\section{Consumption}

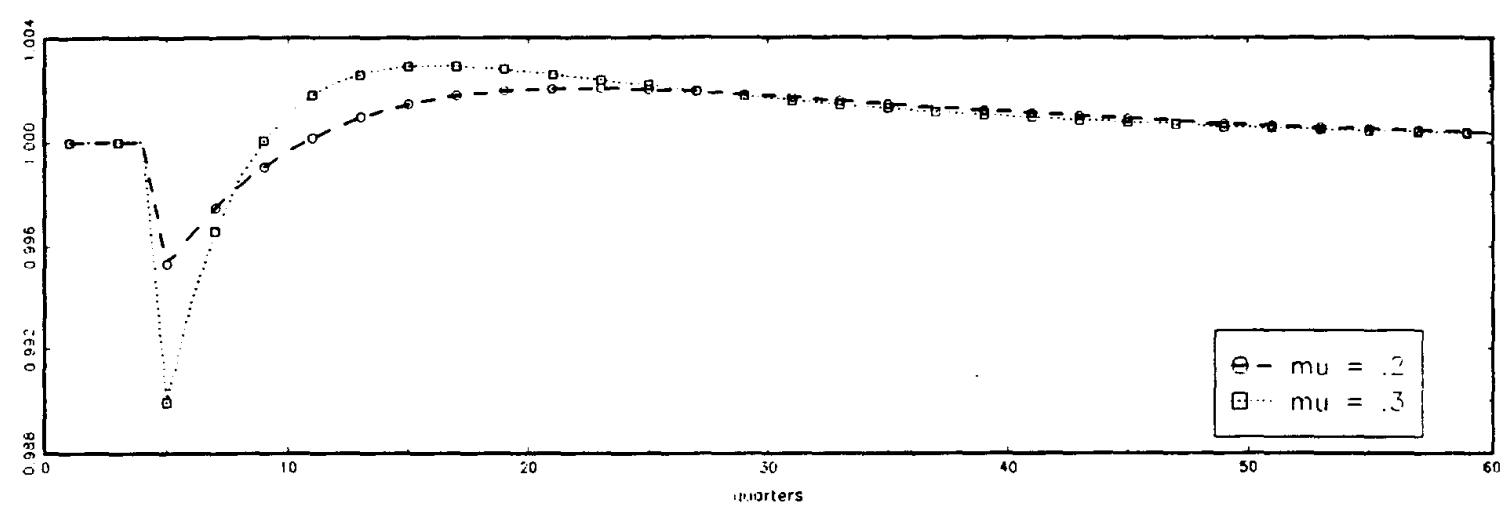

Household labor

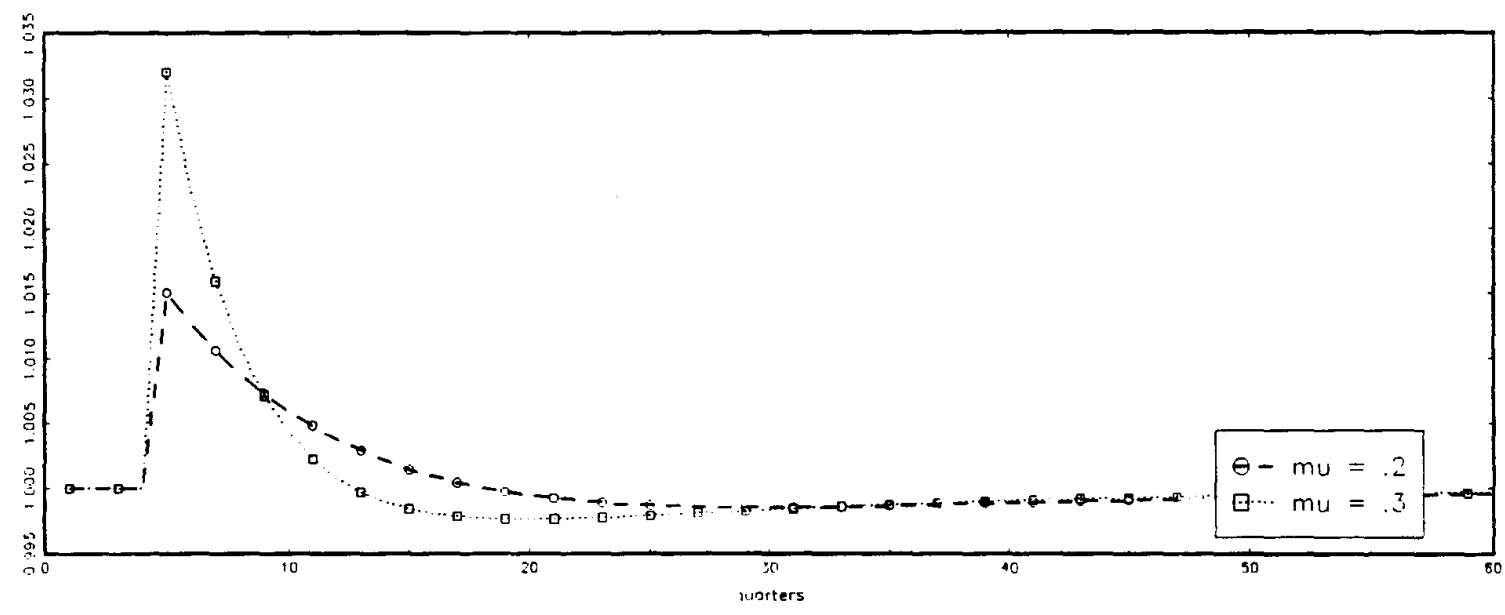

Output

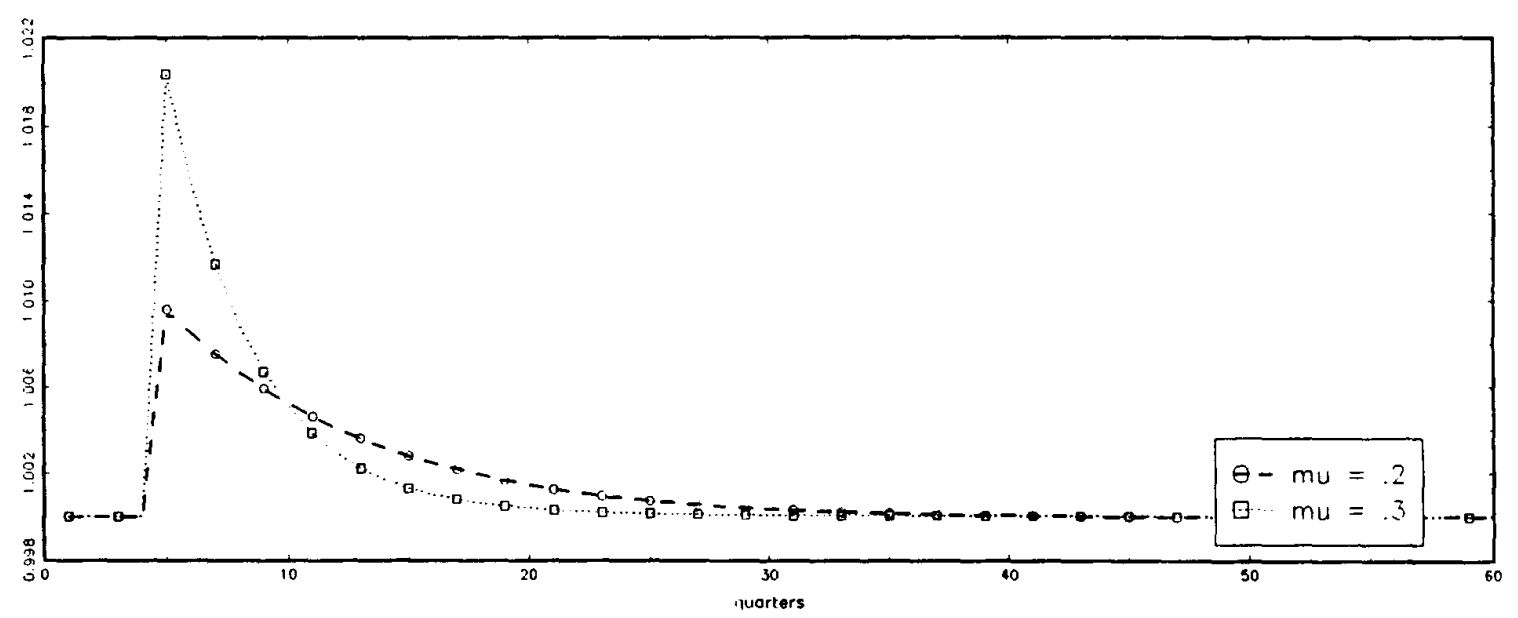

Source: Authors' calculations. 
Figure 3: Productivity Shock $(m u=.2)$

\section{Entrepreneurial net worth}

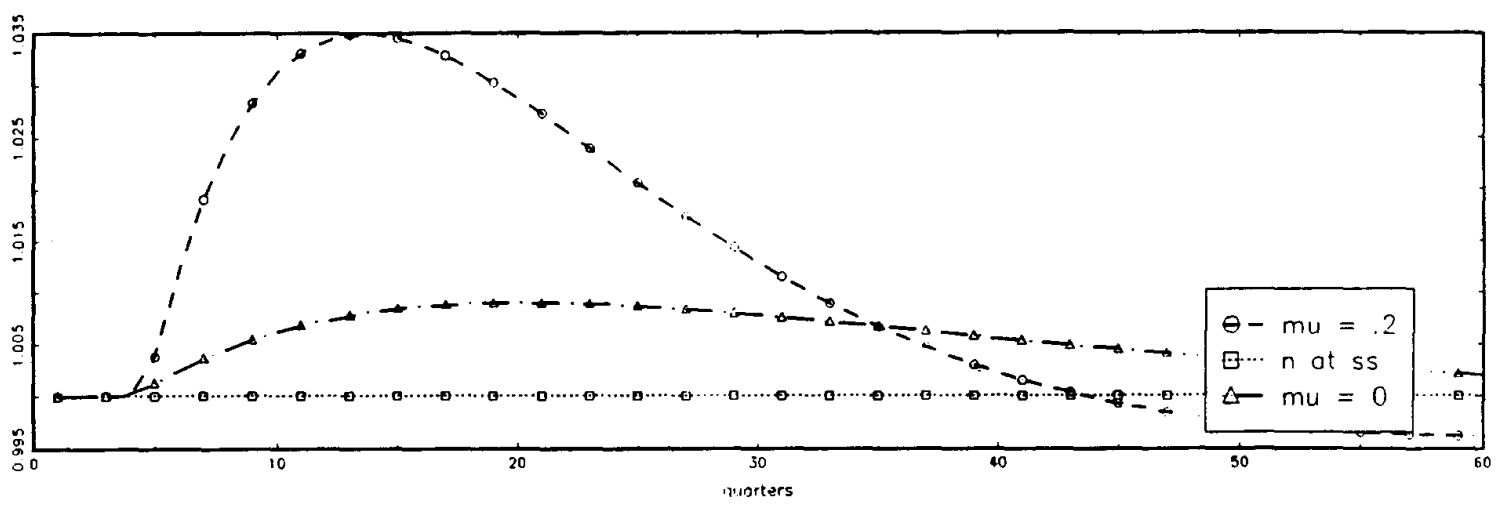

Investment

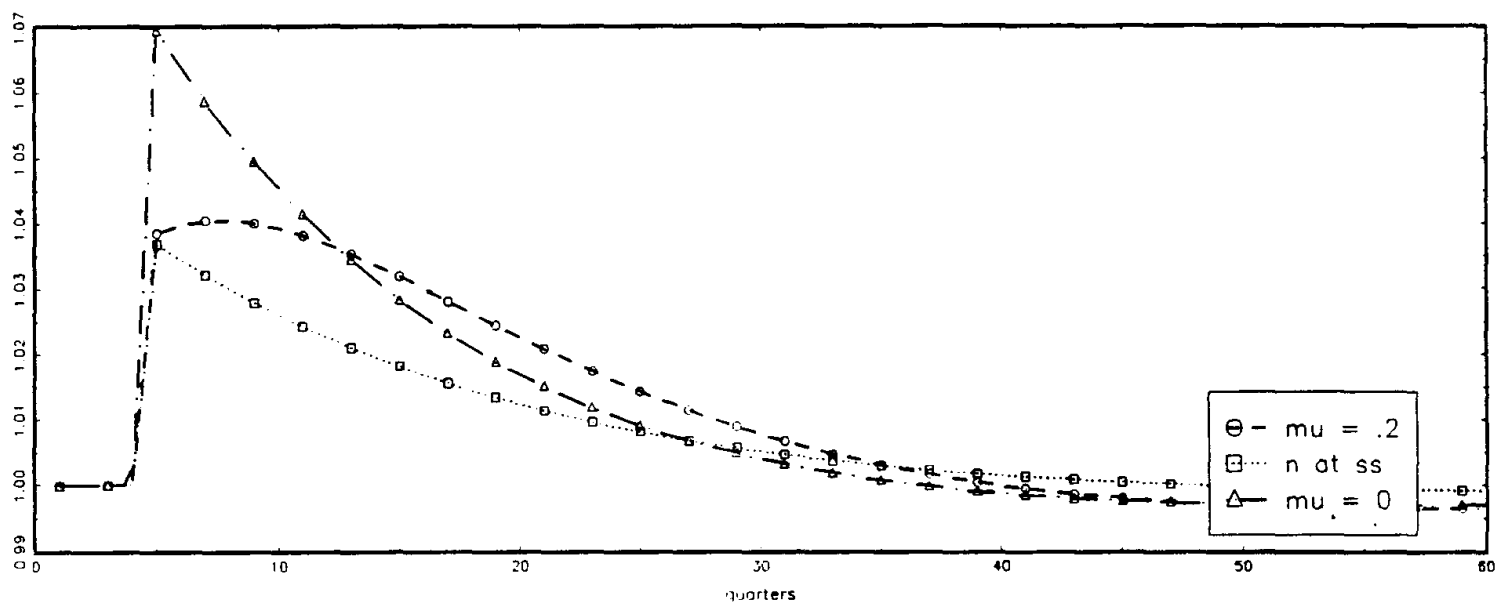

Price of capital

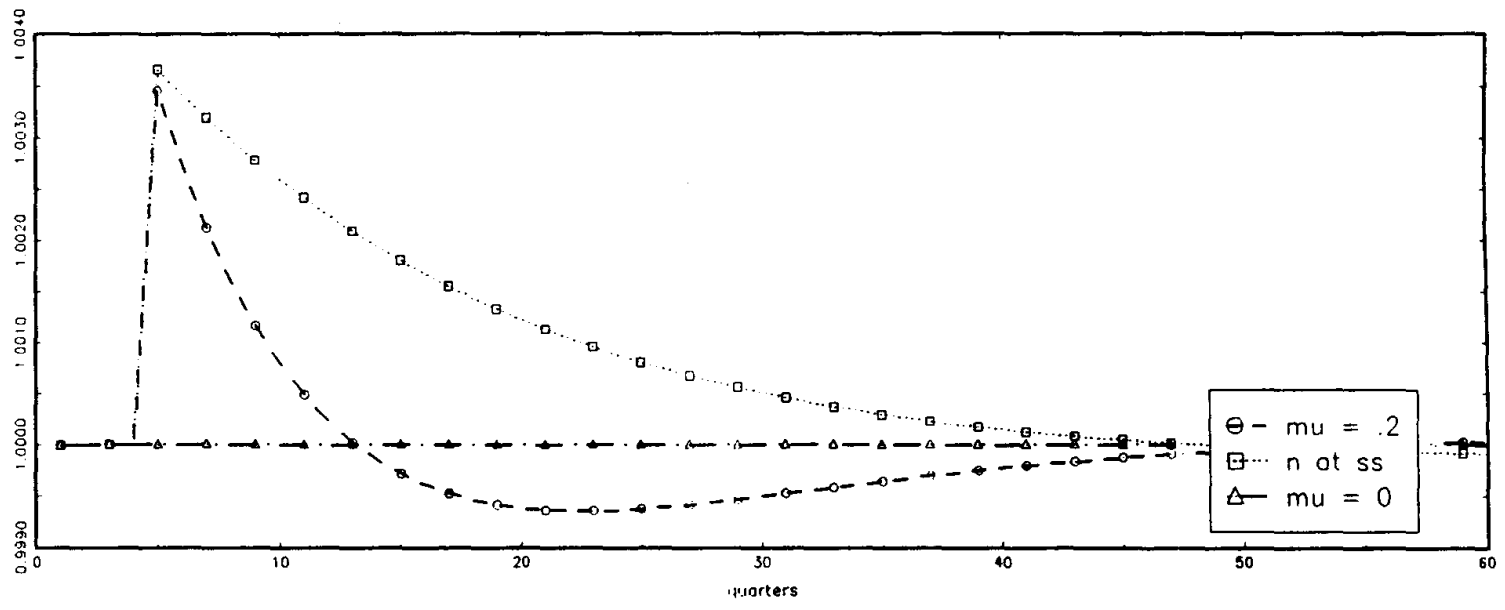


Figure 3: (cont.)

Consumption

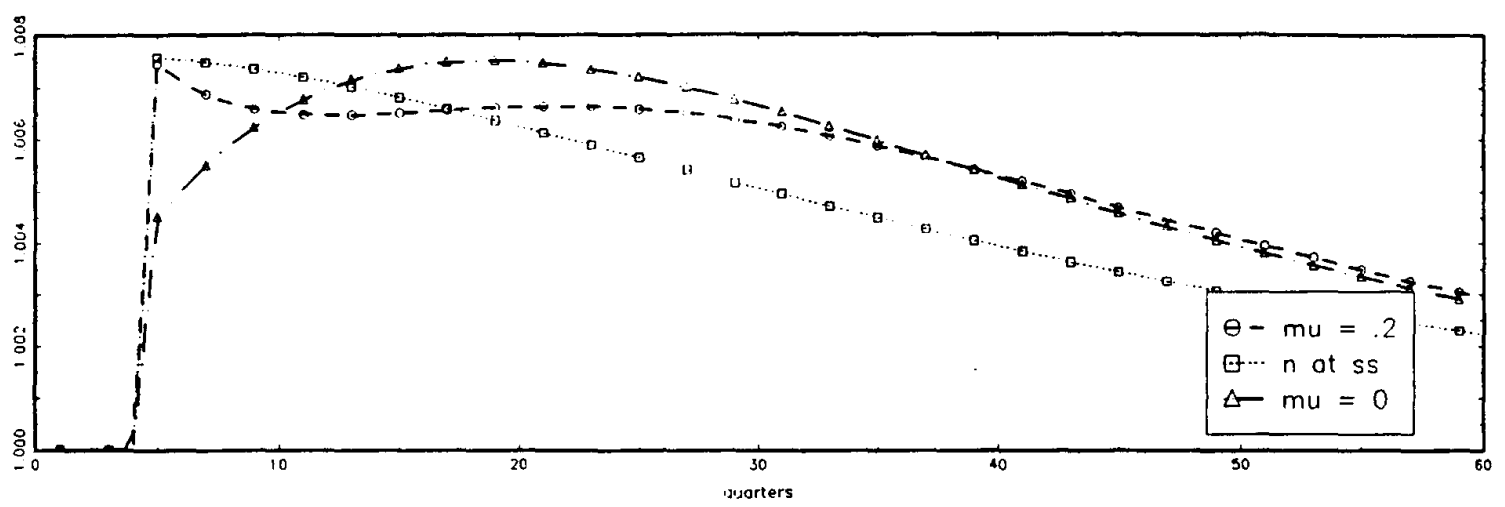

Household labor

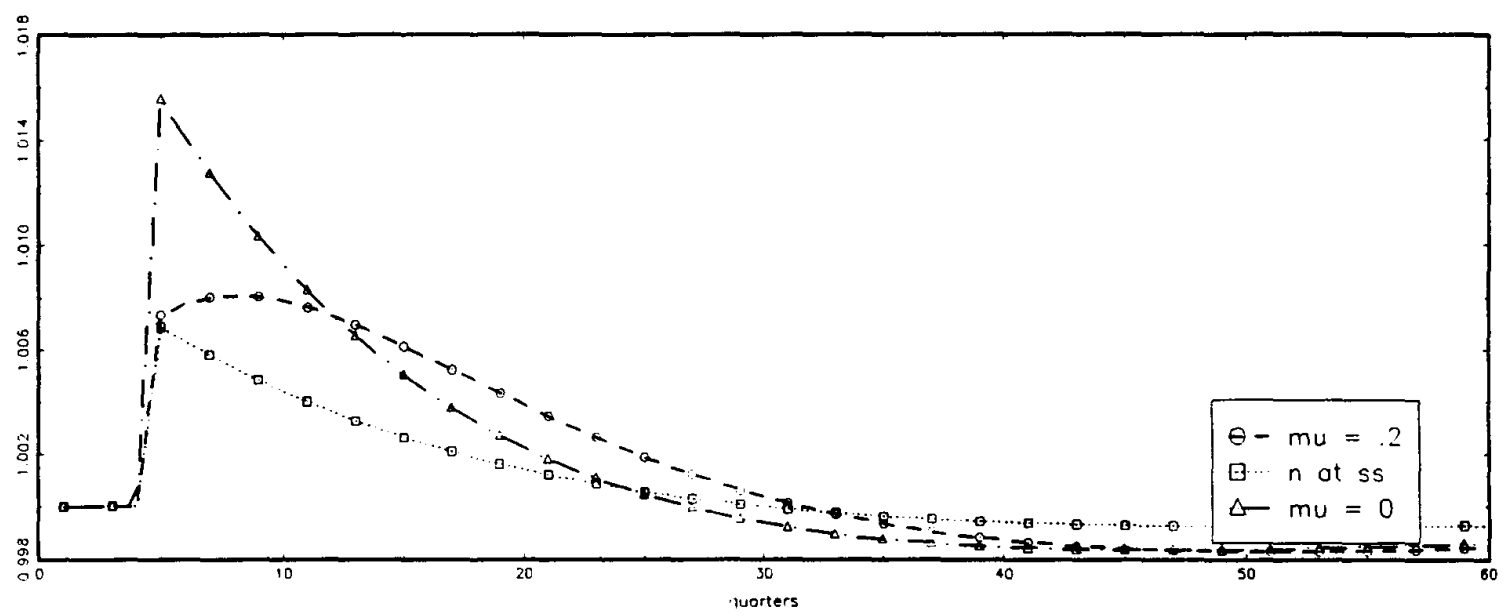

Output

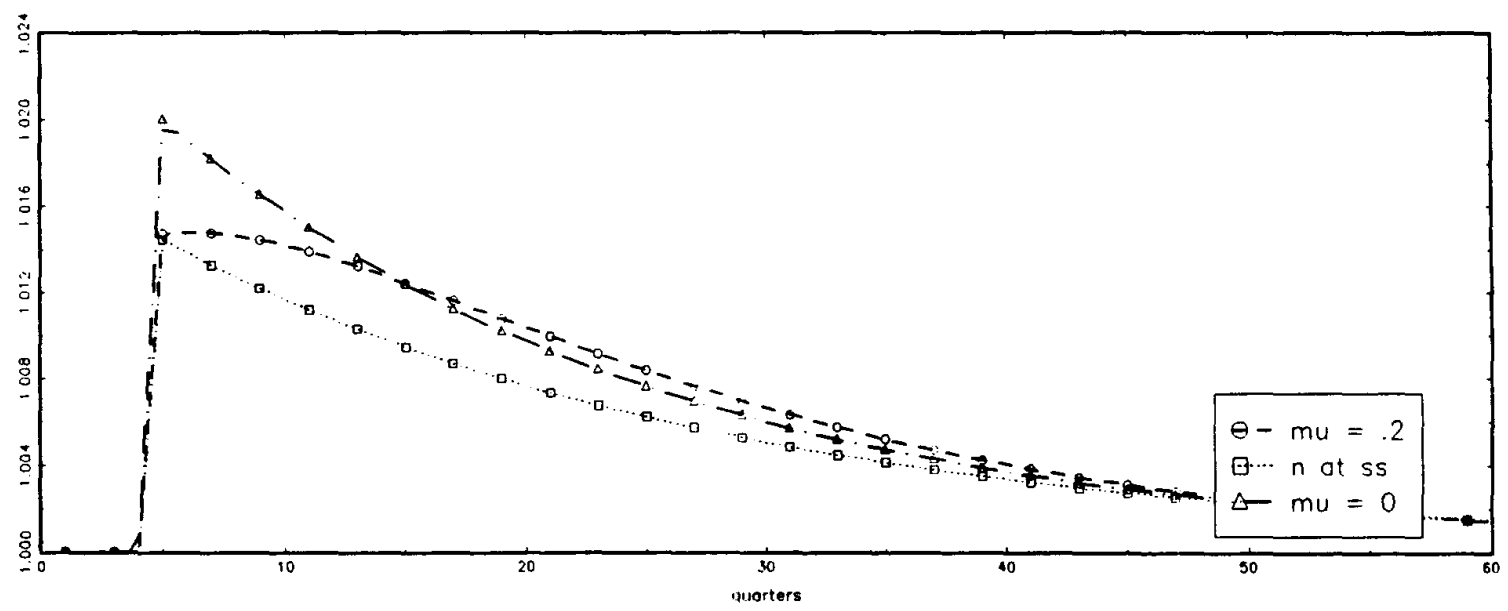

Source: Authors' calculations. 
Figure 4: Productivity Shock $(\mathrm{mu}=.3)$

\section{Entrepreneurial net worth}

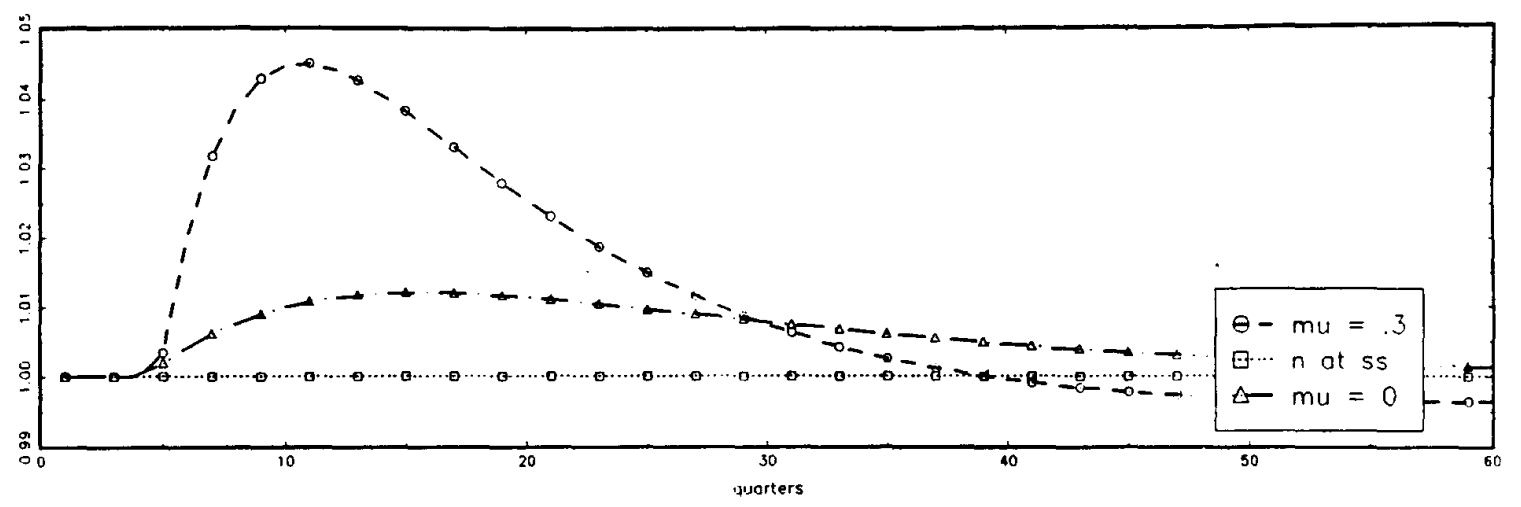

Investment

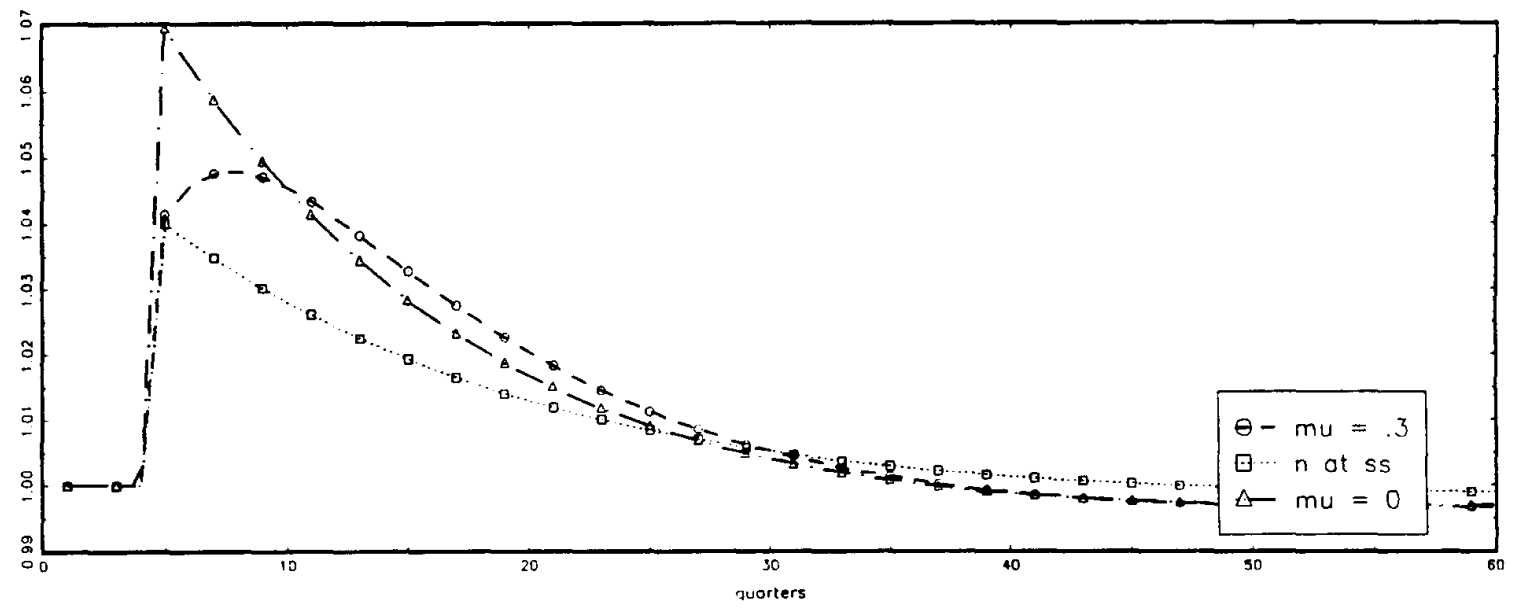

Price of capital

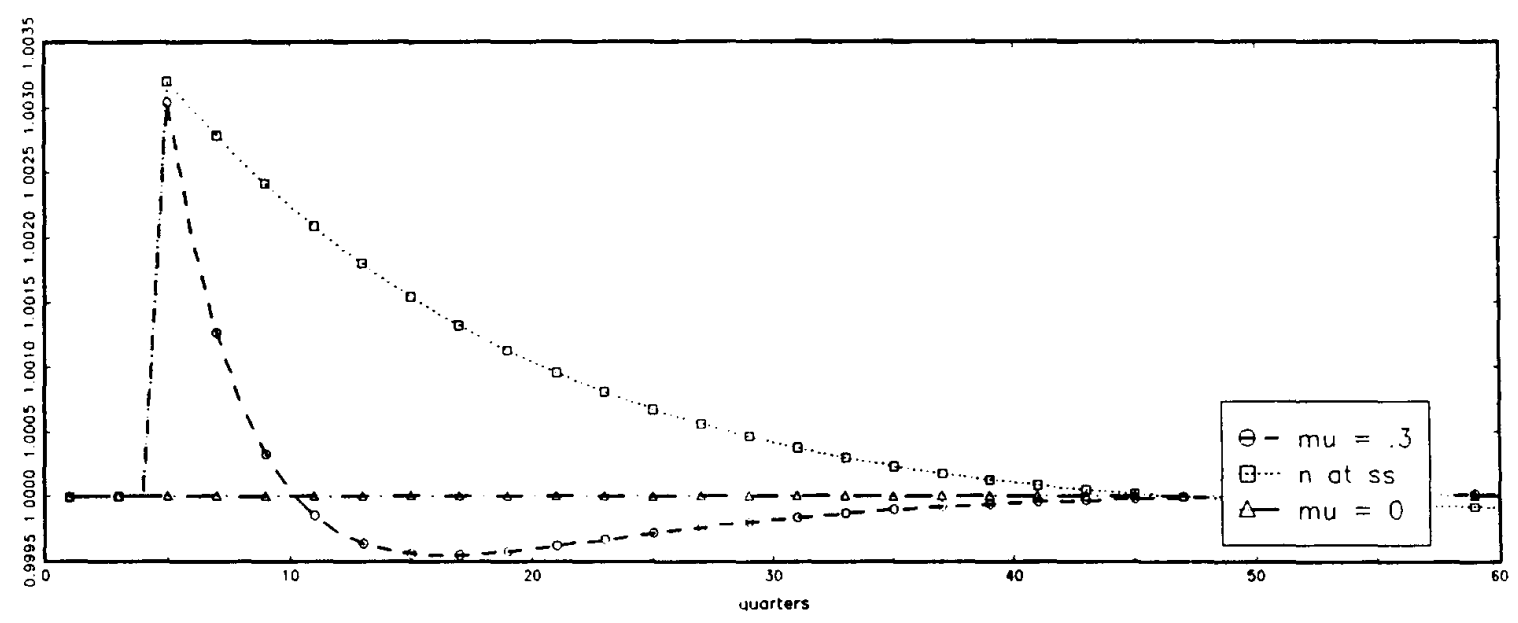


Figure 4: (cont.)

\section{Consumption}

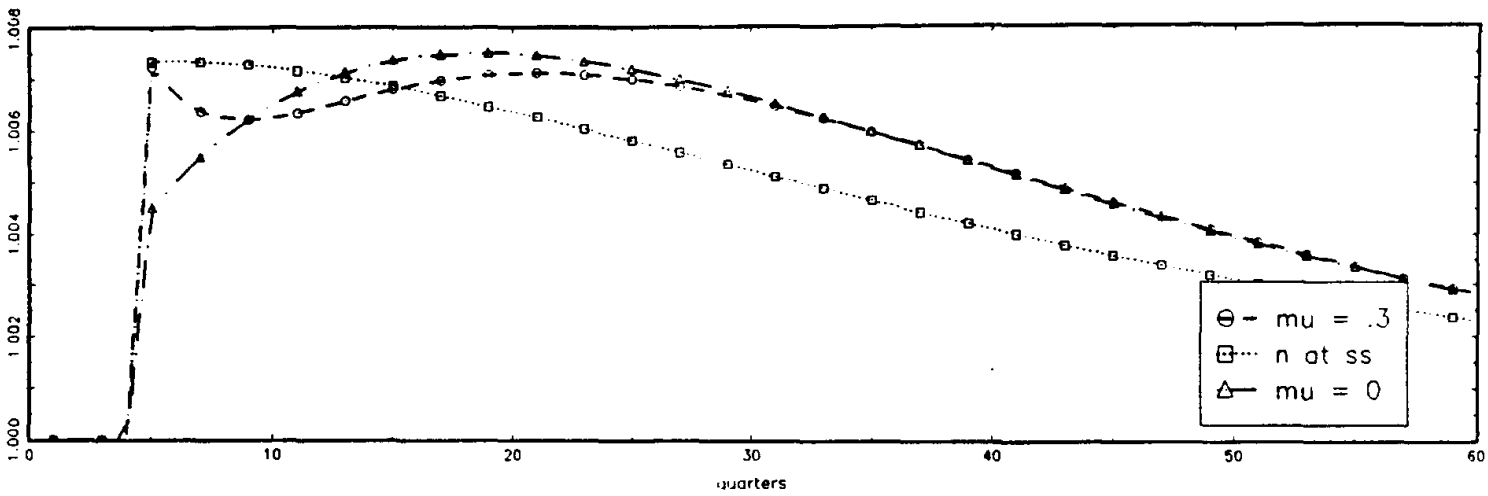

Household labor

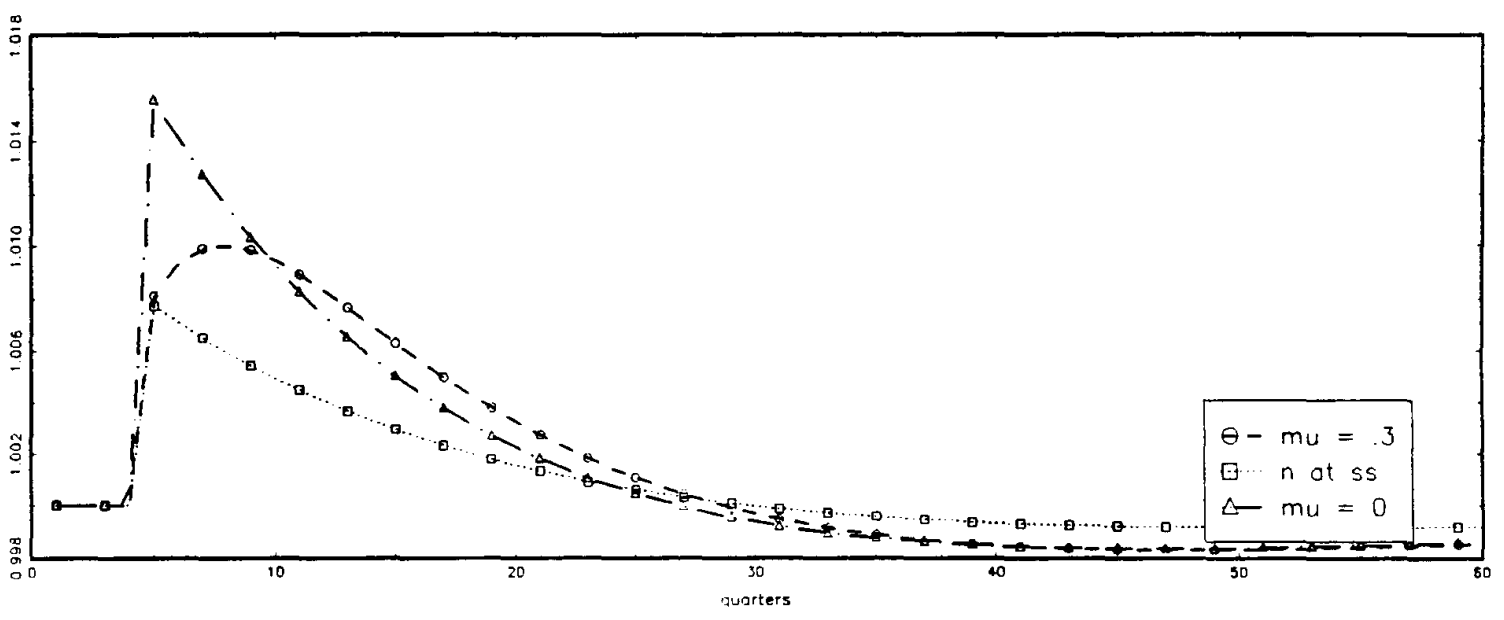

Output

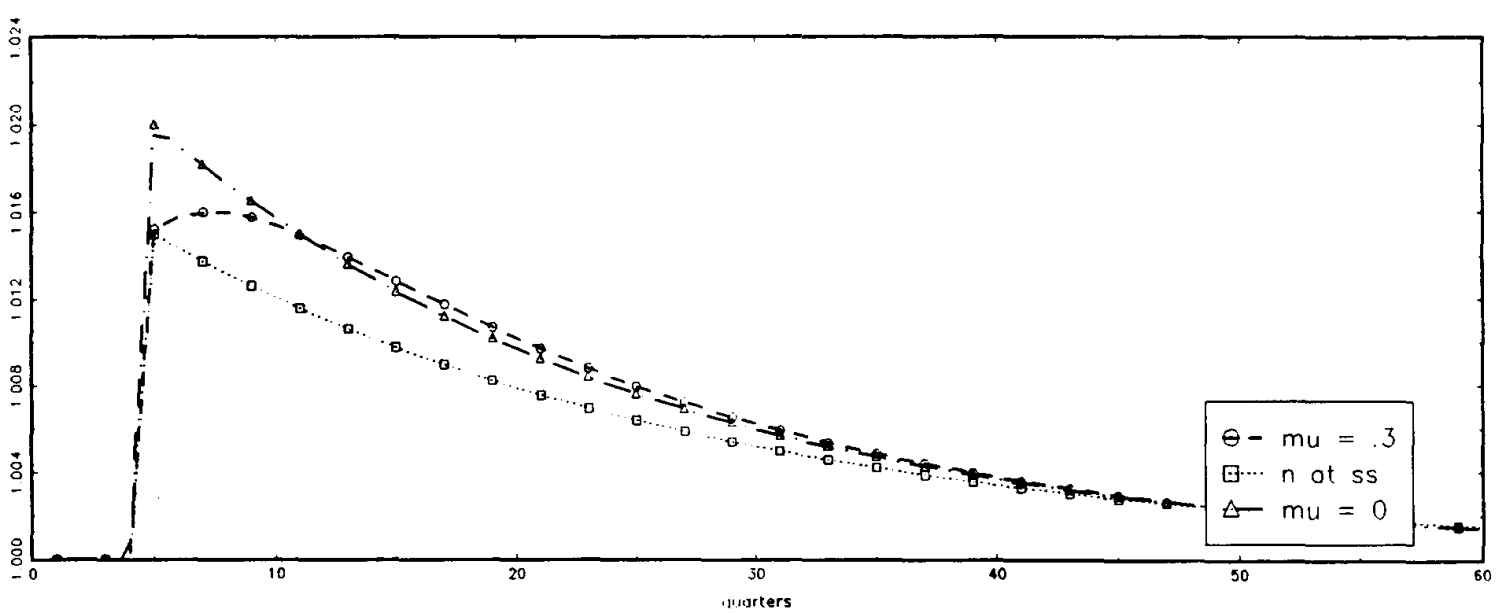

Source: Authors' calculations. 
Table 1: Sensitivity Analysis

\begin{tabular}{|c|c|c|c|}
\hline Simulation & Parameters & Steady State & Comparative Statics \\
\hline High $\mu$ calibration & $\begin{array}{l}\mu=.3, \sigma=0.088 \\
\gamma=0.122 \\
n / i=0.172\end{array}$ & $\begin{array}{l}\mathrm{K}_{\mathrm{ss}}=9.77, \eta \mathrm{n}_{\mathrm{ss}}=.034 \\
\Phi=0.00974, \\
\text { risk premium }=.0157\end{array}$ & $\begin{array}{l}I_{n}(t+1)=24.8 \\
n_{\theta}(t+1)=0.069 \\
I_{\theta}(t+1)=1.71 \\
\varepsilon^{1}=11.5\end{array}$ \\
\hline Low $\mu$ calibration & $\begin{array}{l}\mu=.2, \sigma=0.211, \\
\gamma=0.053, \\
n / i=0.39\end{array}$ & $\begin{array}{l}\mathrm{K}_{\mathrm{ss}}=9.85, \eta \mathrm{n}_{\mathrm{ss}}=.07 \\
\Phi=0.00974, \\
\text { risk premium }=.0157\end{array}$ & $\begin{array}{l}I_{n}(t+1)=8.1 \\
n_{\theta}(t+1)=0.087 \\
I_{\theta}(t+1)=0.767 \\
\varepsilon^{1}=9.3\end{array}$ \\
\hline $\begin{array}{l}\text { Sensitivity analysis of } \\
\text { agency costs/the risk } \\
\text { premium }\end{array}$ & $\begin{array}{l}\mu=.2, \sigma=0.088 \\
\gamma=0.085 \\
n / i=0.178\end{array}$ & $\begin{array}{l}\mathrm{K}_{\mathrm{ss}}=9.89, \eta \mathrm{n}_{\mathrm{ss}}=.035 \\
\Phi=0.00974, \\
\text { risk premium }=.0108\end{array}$ & $\begin{array}{l}\mathrm{I}_{\mathrm{n}}(\mathrm{t}+1)=23.5 \\
\mathrm{n}_{\theta}(\mathrm{t}+1)=0.061 \\
\mathrm{I}_{\theta}(\mathrm{t}+1)=1.44 \\
\varepsilon^{1}=15.3\end{array}$ \\
\hline $\begin{array}{l}\text { Sensitivity analysis of } \\
\text { steady-state bankruptcy } \\
\text { probability }\end{array}$ & $\begin{array}{l}\mu=.2, \sigma=0.072, \\
\gamma=0.137, \\
\mathrm{n} / \mathrm{i}=0.132\end{array}$ & $\begin{array}{l}\mathrm{K}_{\mathrm{ss}}=9.81, \eta \mathrm{n}_{\mathrm{ss}}=.026 \\
\Phi=0.015, \\
\text { risk premium }=.0157\end{array}$ & $\begin{array}{l}I_{n}(t+1)=33.8 \\
n_{\theta}(t+1)=0.057 \\
I_{\theta}(t+1)=1.91 \\
\varepsilon^{1}=15.8\end{array}$ \\
\hline
\end{tabular}

Note: $\mathrm{I}=$ investment, $\mathrm{n}=$ net worth, $\sigma=$ standard deviation of $\omega$

$\omega \sim \log$ normally distributed

$$
\begin{aligned}
& n / i=\frac{n_{s s}}{i_{s s}} \\
& \mathrm{I}_{n}^{s}(t+1)=\frac{\partial \ln I^{s}(t+1)}{\partial n(t+1)} \\
& \mathrm{I}_{\theta}^{s}(t+1)=\frac{\partial \ln I^{s}(t+1)}{\partial \ln \theta(t)} \\
& n_{\theta}(t+1)=\frac{d n(t+1)}{d \ln \theta(t)} \\
& \varepsilon^{\prime}=\frac{\partial \ln I^{s}(t)}{\partial \ln q(t)}
\end{aligned}
$$

Source: Authors' calculations. 